\title{
La compra de oficios como vía de acceso a las varas de justicia. Venalidad y coaliciones políticas en un cabildo rioplatense: la "casa de los Monje" (Santa Fe, 1700-1750)
}

Darío G. Barriera* María Celeste Forconi**

Recibido: mayo de 2014

Aprobado: enero de 2015

Resumen: Este artículo intenta poner en evidencia los mecanismos a través de los cuales un clan familiar (los Martínez del Monje) pudo conseguir una presencia casi hegemónica de sus en funciones judiciales locales - seculares y eclesiásticas- en Santa Fe del Río de la Plata. El trabajo constituye un aporte al estudio de la venalización de cargos judiciales así como al de las dinámicas del poder político en una sede periférica de la Monarquía hispánica durante la primera mitad del siglo XVIII.

Palabras clave: Poder político, alcaldes, jueces eclesiásticos, cabildo, Siglo XVIII

* Darío G. Barriera es Doctor en Historia por la EHESs (París). Revista como Investigador Independiente en el ISHIR (CONICET), Profesor Ordinario de Historia de América II (Colonial) en la Universidad Nacional de Rosario (Argentina) y, en la misma Casa, dirige el Centro de Estudios de Historia Social de la Justicia y el Gobierno (CEHISO-JG, UNR). dgbarriera@conicet.gov.ar

** María Celeste Forconi es Doctora en Historia por la Universidad Nacional de Rosario (UNR), Argentina y revista como Profesora Adscripta en la Cátedra de Historia de América II (Colonial) en la carrera de Historia de la Universidad Nacional de Rosario (Argentina). En la misma Casa, es Secretaria de Extensión del Centro de Estudios de Historia Social de la Justicia y el Gobierno (CEHISO-JG, UNR).mcforconi@hotmail.com

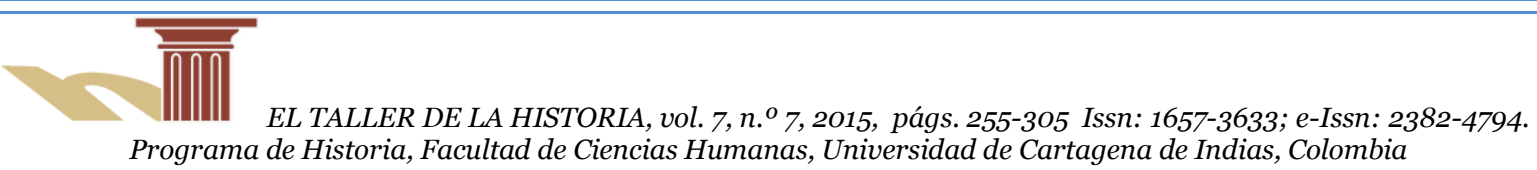




\title{
Buying trades as a Gateway to the justice Venality and political coalitions in a South American council The "casa de los Monje" (Santa Fe, 1700-1750)
}

\begin{abstract}
This article attempts to highlight the mechanisms through which a family clan (the Martinez del Monje) could get an almost hegemonic presence in their local judicial functions -secular and ecclesiastical- in Santa Fe del Río de la Plata. The work is a contribution to the study of venality of judicial positions as well as the dynamics of political power in a peripheral seat of the Spanish monarchy during the first half of the eighteenth century.
\end{abstract}

Key words: Political power, judges, ecclesiastical judges, Council, XVIII century

\section{Presentación}

[...] ha más de diez años sino ha veinte que la dicha vara de Alcalde de Primer Voto está vinculada a esta Casa de los Monjes, pasando de unos a otros entre hermanos, cuñados, tíos, primos, yernos, sobrinos y parientes practicando lo mismo con la de segundo voto.

Antonio Candioti y Mujica, 1745 .

"El dinero proporciona a menudo la llave que abre las puertas del poder político y el estatus social. Nada tan sorprendente como para que merezca la pena detenerse mucho en ello". ${ }^{1}$ Con esa frase, Mauro Hernández sintetiza lo frecuente y lo visible que se había vuelto adquirir un oficio de funcionario para intentar controlar un concejo, pero también ironiza sobre el interés del tema² que, claro está, requiere de

\footnotetext{
${ }^{1}$ Mauro Hernández, "Venalidad de oficios municipales en la Castilla del siglo XVIII: un ensayo de cuantificación”, en Chronica Nova n. ${ }^{0} 33$, Granada, Universidad de Granada, 2007, p.96.

2 Sintetiza bien el mismo autor: "[...] práctica de otorgar a cambio de dinero empleos públicos, en ocasiones temporales pero más frecuentemente vitalicios y aún hereditarios. La venalidad es el origen por tanto de lo que se ha llamado patrimonialización de los oficios públicos, es decir, su conversión en bienes privados (y de carácter raíz): en la corona de Castilla, bajo diversas fórmulas, la patrimonialización de los oficios arranca de al menos el siglo XV, pero a partir de 1543 en que Carlos V introduce como expediente hacendístico de urgencia las ventas de oficios, ambas se convierten en
} 
toda nuestra atención porque la sociedad hispanoamericana del siglo XVIII debe resultarnos antropológicamente esquiva: hay mucho para indagar y aquello que parece natural todavía debe ser interpelado con interrogantes. En lo que concierne a uno de los campos que cultivamos, el de la historia social de la justicia, el acceso venal a los oficios jurisdiccionales constituye uno de los temas que aún requiere de estudios de casuística que son conditio sine qua non para el posterior desarrollo de comparaciones.

Si bien sobre los oficios de justicia pesaba una indisponibilidad para convertirse en venales y patrimoniales ${ }^{3}$ - para el Río de la Plata, por caso, Tau Anzoátegui y Eduardo Martiré sostuvieron con razón que jamás se vendió un oficio de alcaldeinvestigaciones inspiradas en esa misma historiografía (que permitió ir más allá de los ordenamientos legales para adentrarse en las prácticas sociales que lógicamente interactuaban con dicho ordenamiento) reveló casos que nítidamente pueden identificarse con ventas más o menos veladas de oficios jurisdiccionales en diferentes territorios de la monarquía. 4

Con este trabajo, entonces, no pretendemos señalar una anomalía, sino analizar cómo se articuló en un caso concreto la venta de oficios renunciables con la venalización directa e indirecta de oficios jurisdiccionales (no vendibles) así como al articulación con el campo político secular desde diferentes posiciones eclesiásti-

un fenómeno habitual hasta su definitiva extinción con la revolución liberal del XIX”, Mauro Hernández, "Venalidad de oficios [...]", p.97. Un estado del arte reciente en Antonio Jiménez Estrella, "Poder, dinero y ventas de oficios y honores en la España del Antiguo Régimen: un estado de la cuestión”, en Cuadernos de Historia Moderna n. ${ }^{\circ} 37$, Madrid, 2012, pp.259-272.

${ }^{3}$ Francisco Tomás y Valiente, La venta de oficios en Indias (1492-16o6), Madrid, Instituto de Estudios Administrativos, 1972; Gobierno e Instituciones en la España del Antiguo Régimen, Madrid, Alianza, 1992, pp. 151-177. Entre los estudios que analizan la relación entre venalidad y buen gobierno así como una crítica de su contraposición se destaca el pionero de Francisco Andújar Castillo, Necesidad y venalidad. España e Indias, 1704-1711. Madrid, Centro de Estudios Políticos y Constitucionales, 2008.

${ }^{4}$ Víctor Tau Anzoátegui y Eduardo Martiré, Manual de historia de las instituciones argentinas, $\left(7^{\mathrm{a}}\right.$ edición actualizada), Buenos Aires, Librería Histórica, 2005, p.96; Inés Gómez González, La justicia en Almoneda. La venta de Oficios en la Chancillería de Granada (1505-1834), Granada, Comares, 2002; Antonio Álvarez-Ossorio Alvariño, "La venta de magistraturas en el reino de Nápoles durante los reinados de Carlos II y Felipe v", en Chronica Nova, $\mathrm{n}^{\circ}$ 33. Granada, Universidad de Granada, 2007, pp.57-94, y Darío G. Barriera, "La dimensión política de un oficio de vara en los bordes de la Monarquía hispánica: reflexiones sobre el alguacilazgo mayor en Santa Fe la Vieja (Gobernación del Río de la Plata, 1573-1660)", en Chronica Nova n. ${ }^{\circ}$ 7, Granada, Universidad de Granada, 2011, pp.69-98. 
cas. Hemos estudiado las prácticas de una familia -el cómo- valiéndonos de la documentación que ellos mismos dejaron así como de la que arroja las formas en que su accionar fue percibido por sus adversarios políticos.

\section{Retrato de una familia localmente "notable" y "poderosa"}

En sociedades de Antiguo Régimen, las familias vinculadas con el gobierno de la ciudad pertenecían de hecho y por derecho al grupo de los notables. Si, además, conseguían asociarse -a través del parentesco, la amistad o la compañía- con otras que respondían a algunos de los criterios socialmente distintivos -la vecindad, la participación en el gobierno, la posesión de bienes materiales y culturales o de atributos simbólicos -5 y su incidencia en la toma de decisiones política era conocida y reconocida por sus coetáneos como frecuente, estamos frente a una familia que, además de notable era poderosa.

La familia y las parentelas que pasan por el nudo gordiano del matrimonio celebrado entre Francisco Martínez del Monje e Isabel Pessoa de Figueroa en Santa $\mathrm{Fe}$, pueden legítimamente considerarse dentro de esta categoría: entre 1700 y 1750, las varas de primer y segundo voto de la ciudad de Santa Fe fueron ocupadas por un miembro de este verdadero clan familiar en cuarenta ocasiones, mientras que las sesenta restantes no fueron monopolizadas por otro grupo familiar, motivo por el cual no sólo puede hablarse de presencia permanente sino también preeminente, y por esto mismo, hegemónica. Durante el mismo período, uno de sus miembros (Juan de Lacoizqueta) fue dos veces teniente de gobernador -justicia mayor- otro (Ignacio Martínez del Monje) ejerció como alférez real durante diecisiete años, y entre 1725 y 1749 Miguel Martínez del Monje fue propietario de una regiduría perpetua. ${ }^{6}$ Cuatro miembros de la familia (Hipólito, Juan, Joseph y Pedro Martínez del Monje) estudiaron teología en Córdoba, se graduaron y tres de ellos ingresaron al

\footnotetext{
${ }^{5}$ Darío G. Barriera, Abrir puertas a la tierra. Microanálisis de la construcción de un espacio político (Santa Fe, 1573-1640), Santa Fe, Museo Histórico Provincial, 2013, pp.367-368.

${ }^{6}$ Otro más (Francisco de Bracamonte) fue tesorero de la Real Hacienda durante veintiún años. Sin embargo, aunque parte de la familia, no jugó a favor de la coalición familiar, y por eso no se lo incluye en ese renglón.
} 
clero. Hipólito ingresó a la orden jesuita y los otros tres fueron jueces eclesiásticos en Santa Fe. ${ }^{7}$

Los Martínez del Monje constituyeron un grupo familiar de notables. Su abrumadora presencia en el cabildo santafesino durante dicho medio siglo, puede incluso obnubilar al investigador y fagocitarse su curiosidad. Entonces, en casos como este, la pregunta por la construcción de este cuadro es menos tributaria de una genealogía legitimadora que de una curiosidad sincera. Durante los varios años que trabajamos juntos -como tesista y director-algunas de las preguntas que orientaban la tesis se repetían una y otra vez y tienen todavía hoy una respuesta difícil: la exitosa presencia de miembros de este clan familiar en ámbitos civiles y eclesiásticos generó tanto volumen de actividad que transformaba en árida la búsqueda de una configuración inicial. Si la elección de esta familia como objeto de estudio se basó en su indiscutible visibilidad, la exhumación de las múltiples decisiones que la hicieron visible todavía no está agotada. Con este artículo iluminaremos un punto de intersección entre nuestros intereses: la presencia casi hegemónica de esta familia en el poder político local pero sobre todo monopolizando funciones judiciales.

A lo de "poderosa" -segundo adjetivo del subtítulo-llegaremos por esta vía e iremos luego. Como se verá, en este caso el adjetivo no lo coloca un investigador sino un coetáneo perjudicado por sus comportamientos.

\footnotetext{
${ }^{7}$ Miriam Moriconi, "Usos de la justicia eclesiástica y de la justicia real (Santa Fe de la Vera Cruz, Río de la Plata, s. XVIII)", Nuevo Mundo Mundos Nuevos [en línea], Debates, París, Puesto en línea el 27 octubre 2012, consultado el 11 junio 2013. http://nuevomundo.revues.org/64359; "Diversidad institucional y conflictos jurisdiccionales. El clero santafesino en el siglo XVIII", en Gabriela Alejandra Caretta y Isabel Zacca (comps.), Derroteros en la construcción de religiosidades sujetos, instituciones y poder en Sudamérica, siglos XVII al XXI, Salta, Centro Promocional de Investigaciones en Historia y Antropología -CEPIHA, 2012.
} 


\section{Un migrante logroñés}

Francisco Martínez del Monje, fundador de esta familia santafesina, era natural de la villa de San Vicente de la Sonsierra - provincia de Logroño, España- y fue bautizado el 20 de octubre de 1640 en la Parroquia de Santa María la Mayor. ${ }^{8}$ Falleció en Santa Fe el 27 de enero de $1695 .{ }^{9}$

Fue uno de los hijos legítimos de Pedro del Monje y de María de Davalillo. Según Burzaco y Barrios, "[...] llegó a Buenos Aires en 1663 a bordo del navío del Cap. Ignacio Mateo [...]", ${ }^{10}$ y el 20 de agosto de 1666, ${ }^{11}$ Francisco Martínez del Monje contrajo matrimonio con Isabel de Pessoa y Figueroa, ${ }^{12}$ proveniente del seno de una de las familias por entonces políticamente influyentes en un territorio que iba de la capitanía de Chile al Paraguay, pasando por Cuyo y el Río de la Plata.

El abuelo de Isabel, Pedro Homen de Pessoa de Saa, había nacido en Santiago de Chile en 1593 y pasado luego a San Luis, donde fue lugarteniente del capitán general, corregidor y justicia mayor de Cuyo entre los años 1628 y 1631; se trasladó a Buenos Aires -donde fue alcalde en 1635- y hasta se desempeñó como teniente de gobernador de Santa Fe entre 1646 y 1648. Nicolás de Pessoa y Figueroa, padre de Isabel, nació en Santiago de Chile por 1620, se radicó primero en Santa Fe y fue teniente de gobernador entre 1646 y $1648 .{ }^{13}$ Un año después contrajo matrimonio con Juana de Ávila y Sotomayor, madre de Isabel. Luego, el General Pessoa se estableció en el Paraguay, donde fue vecino encomendero de Villarrica del Espíritu

\footnotetext{
${ }^{8}$ El lugar de nacimiento surge de un testimonio que dio Francisco en el informe de soltería de Pedro de Leiva para casarse con Felipa de Robles. Archivo de la Catedral Metropolitana de Santa Fe (ACM), Matrimonios (M), 1680-1690, Libro I, exp.125. Coincidimos con Luís María Calvo, "Martínez del Monje", en Boletín del Instituto Argentino de Ciencia Genealógicas vol.XII, n. ${ }^{\circ} 158$, Buenos Aires, 1988, p. 58. Otros genealogistas - como Carlos Ibarguren (h) - sugieren que sería natural de la villa de Santo Domingo de la Calzada, pero no cita documentación.

${ }^{9}$ Archivo General de la Provincia de Santa Fe (AGSF) Actas Capitulares (AC) tomo VI, ff.46v.-49.

${ }^{10}$ Hugo Fernández de Burzaco y Barrios, "Fundadores de linajes en el Plata", en Genealogía n. ${ }^{\circ 11}$ Buenos Aires, 1955, pp.160-161, se equivoca con la fecha de casamiento de Francisco e Isabel.

${ }^{11}$ ACM, Matrimonios, 1642-1715, ff.10v. (51v).

12 Hija de Nicolás de Pesoa y de Juana Dávila, bautizada en la catedral de Todos los Santos, Santa Fe, el 9 de julio de 1650.

${ }^{13}$ AGSF, AC, tomo III, ff.51, 97.
} 
Santo. Después de enviudar contrajo segundas nupcias con Da. Francisca de Sanabria y Saavedra, matrimonio que dio a Isabel tubo tres hermanos varones influentes -Ignacio de Pessoa y Figueroa (canónigo de la catedral de Buenos Aires); ${ }^{14}$ León de Pessoa y Figueroa (canónigo de la catedral de Lima) y Juan de Pessoa y Figueroa que fue alcalde y regidor de Corrientes. A partir del 25 de julio de 1691 fue teniente de gobernador, capitán a guerra y justicia mayor de Corrientes. ${ }^{15}$

El matrimonio le permitió ser vecino en Asunción del Paraguay, en cuyo cabildo ocupó una silla de regidor y el oficio de alguacil mayor entre 1675 y $1677 .{ }^{16} \mathrm{La}$ conexión entre Francisco y el Paraguay no es casual ni es un hecho aislado: su matrimonio en Santa Fe lo había transformado en uno de los "engranajes del circuito de la yerba". Cuando a comienzos de 1682 los capitulares de Asunción elevaron ante el Rey Carlos II su queja por la suba de los impuestos sobre la yerba mate, el poder otorgado al procurador general fue firmado hombres "[...] vecinos de Santa Fe, relacionados al Paraguay por casamientos, y en el caso de los hermanos Domínguez por estrechos lazos de sangre de abuelos paraguayos". ${ }^{17}$

No sabemos exactamente cuándo se asentó Francisco en Santa Fe, pero sí que ingresó en la vida capitular en 1680. Lo hizo en un puesto exigente y prestigioso, el de procurador general. ${ }^{18} \mathrm{El} 7$ de septiembre de 1683 se constituyó en fiador del escribano Francisco de Angulo y, en 13 de diciembre del mismo año el capitán

14 Departamento de Estudios Etnográficos y Coloniales de Santa Fe (DEEC, SF), Escrituras Públicas (EP), tomo XI, ff.390-392

${ }^{15}$ Luis María Calvo, "Martínez del Monje”, p.59. En una escritura de venta figura como vecino de la ciudad de Corrientes. DEEC, SF, EP, tomo XI, ff.437-438.

16 Roberto Quevedo, Paraguay años 1671 a 1681, Asunción, El lector, 1983, p.36. El padre Pastells afirma que en 1677 todavía era alguacil mayor en Asunción. El gobernador paraguayo Felipe Rexe Corvalán lo incluye en la lista de quienes querían "arruinar" su gobierno. Pablo Pastells, Historia de la Compañía de Jesús en la provincia del Paraguay (Argentina, Paraguay, Uruguay, Perú, Bolivia y Brasil). Según los documentos originales del archivo general de indias extractados y anotados por el R.P. Pablo Pastells, S.J., Tomo III, Madrid, Librería General de Victoriano Suárez, 1918, p.129.

17 Roberto Quevedo, Paraguay años 1671 a 1681, p.56.

18 AGSF, AC, tomo v, ff.75v.-77v. Este oficio era el portavoz del la ciudad, formulaba peticiones de interés colectivo y proponía mejoras ante el gobernador, otros cabildos u otras autoridades. Manuel María Cervera, Historia de la ciudad y provincia de Santa Fe. Contribución a la Historia de la República Argentina 1573-1853, 2ª edición, tomo II, Santa Fe de la Vera Cruz, UNL, 1980 [1907], p.30. 
J. Domínguez Pereira presentó un auto de la Real Hacienda de Buenos Aires que designaba a Francisco Martínez del Monje teniente de oficiales reales (tesorero). ${ }^{19}$

En 1687 consiguió ocupar el cargo de alcalde de primer voto. Sin embargo, pudo blandir la vara solo después de atravesar por varios conflictos resueltos por una regulación del teniente de gobernador Francisco Izquierdo. ${ }^{20}$ Se había dado una doble paridad de votos entre el capitán Juan de Ávila y Salazar y el sargento mayor Miguel Martínez de Roza (encomendero) para la alcaldía de primer voto y entre los capitanes don Francisco Martínez del Monje y Pedro de Mitre para la de segundo. La primera regulación del teniente fue a favor de Martínez y de Mitre. Francisco Martínez del Monje apeló la elección ante la Real Audiencia de La Plata, sobre lo cual el cuerpo le respondió "[...] que el día de la eleccion votamos por aquellas personas que nos parecieron mas justas y dignas de los oficios en que fueron electos". ${ }^{21}$ Aunque los términos de la apelación no fueron transcriptos en el libro capitular, la respuesta permite inferir que Martínez del Monje había denunciado el parentesco entre los alcaldes electos y el teniente de gobernador.

La confianza de Francisco en su apelación mutó en osadía y participó de la "procesión del tránsito" junto a los alcaldes electos. La crónica registró que durante la misma "se hallaron cuatro alcaldes ordinarios con varas de justicia en la mano". ${ }^{22}$ Seguramente movido por la publicidad y el carácter escandaloso del hecho, el teniente de gobernador Francisco Izquierdo propuso averiguar las circunstancias del caso y, finalmente, el 23 de agosto de 1687 el mismo cabildo acató la Real Provisión dictada por la Audiencia de La Plata, que anulaba la elección y confirmaba a Francisco Martínez del Monje como alcalde de segundo voto. ${ }^{23}$

Cuatro años más tarde, Francisco fue designado nuevamente procurador general. ${ }^{24}$ En esta oportunidad (1691), se lo designó para que, junto con el alcalde de segundo voto, diera la bienvenida y presentara la descripción del estado de la ciu-

\footnotetext{
${ }^{19}$ AGSF, AC, tomo v, ff.141, 157-16o, respectivamente.

${ }^{20}$ AGSF, AC, tomo v, f.268v.

${ }^{21}$ AGSF, AC, tomo v, f.249 v., resaltado nuestro.

22 AGSF, AC, tomo V, f.262, énfasis nuestro.

${ }^{23}$ AGSF, AC, tomo v, ff.264-268v.

${ }^{24}$ AGSF, AC, tomo v, ff.380v.-381.
} 
dad y de sus necesidades al nuevo gobernador Agustín Robles, que visitaba Santa Fe. ${ }^{25}$ En 1695 fue nuevamente alcalde de primer voto y revistó como capitán de milicias, ${ }^{26}$ con lo cual sumó prestigio ligado al mando de hombres armados.

\section{La suma de hombres para los asuntos del siglo: hijos e hijos políticos}

No obstante la importancia de sus logros individuales y de la resonancia de sus intervenciones en el cabildo, su consolidación en la sociedad santafesina se registra cuando su actividad política supera la dimensión personal para integrar el juego de un grupo. Su tarea fue, justamente, la de imagina y ejecutar esa configuración.

Francisco transitó el camino que por entonces era considerado el más seguro en esta línea. ${ }^{27}$ Trató de ampliar el número de deudos a través de alianzas con otras familias y promoviendo su inserción en los corpora proveedores de prestigio y honorabilidad. Para lo primero organizó los matrimonios de algunos de sus hijos y de sus hijas, y para lo segundo dispuso que cuatro de sus hijos estudiaran Teología. De la vasta descendencia de su matrimonio con Isabel (diez hijos) solamente 5 (cinco) contrajeron matrimonio: dos varones (Ignacio y Miguel) y tres mujeres (Ana, Francisca y María -las últimas se casaron dos veces, lo mismo que Miguel-).

${ }^{25}$ AGSF, AC, tomo v, f.388v.

${ }^{26}$ Juan Carlos Crespo Naón, La sociedad santafesina: génesis y evolución. Buenos Aires, SNT, 1983, p.51.

${ }^{27}$ Griselda Tarragó y Darío Barriera, "Elogio de la incertidumbre. La construcción de la confianza, entre la previsión y el desamparo: Santa Fe y el Río de la Plata, siglo XVIII", en Revista de Historia n. ${ }^{\circ}$ 48, San José, Universidad Nacional de Costa Rica, 2003, pp.183-223. 
Tabla 1:

Matrimonios de los hijos e hijas de Francisco Martínez del Monje e Isabel de Pessoa

\begin{tabular}{||l|c|c||}
\hline \multicolumn{1}{|c|}{ Hombre } & Fechas matrimonio & Mujer \\
\hline Antonio Pérez & $24 / 8 / 1681$ & María Martínez del Monje \\
\hline Juan de Rezola & $2 / 10 / 1689$ & Francisca Martínez del Monje \\
\hline Juan Lacoizqueta & $19 / 12 / 1691$ & María Martínez del Monje \\
\hline Ignacio Martínez del Monje & $20 / 12 / 1697$ & María Suárez de Cabrera \\
\hline Pedro Urizar & $22 / 12 / 1709$ & Ana Martínez del Monje \\
\hline Francisco Bracamonte & $15 / 9 / 1712$ & Francisca Martínez del Monje \\
\hline Miguel Martínez del Monje & $1^{\circ}$ matrimonio & María de Rojas Aranda \\
\hline Miguel Martínez del Monje & $\begin{array}{c}25 / 12 / 1730 \\
2^{\circ} \text { matrimonio }\end{array}$ & Dominga de Mendieta y Zarate \\
\hline \hline
\end{tabular}

Fuente: elaboración propia con base en ACM, Matrimonios, 1642-1715 y 1717-1732.

\section{La llave de las hijas}

\section{a) Francisca y sus dos maridos}

Francisca Martínez del Monje, novena hija del matrimonio entre Francisco Martínez del Monje e Isabel de Pessoa, ${ }^{28}$ fue casada el 2 de octubre de 1689 con don Juan de Rezola, natural de la provincia de Guipúzcoa, hijo de Iñigo de Rezola y de Ana de Hurteaga. ${ }^{29}$ En su testamento, Rezola declaró que al contraer el matrimonio "[...] no tubo bienes ni caudal ninguno suio mas que el bestuaria de su huso" Sin embargo, según la testamentaria de Rezola, Francisca fue dotada el 2 de octubre de 1689 con $\$ 6.204$, a los que su marido agregó $\$ 1.000$ en arras..$^{30}$

\footnotetext{
${ }^{28}$ Carta de testamento de Isabel de Pessoa y Figueroa, otorgada en Santa Fe el 16 de mayo de 1729. DEEC, SF, EP, tomo X, ff.694-697v.

${ }^{29}$ ACM, M, 1680-90, libro I, exp.120.

30 Testamentaria de Juan de Rezola, DEEC, SF, EP, tomo vIII, ff.560-563v.
} 
A Rezola, comerciante de yerba con buen volumen de negocios, ${ }^{31}$ el casamiento con Francisca le reportó prestigio y acceso al cabildo como miembro de la coalición que organizaba su suegro. También él estuvo vinculado con la administración de justicia ordinaria de la ciudad: en 1697 desempeñó el cargo de alcalde segundo y en 1706 el de primer voto. En 1701 fue designado procurador general de la ciudad. ${ }^{32}$ Desde 1707 hasta su muerte (1710), ${ }^{33}$ ocupó el cargo clave de tesorero de la Real Hacienda. Además, desde 1705 fue síndico del convento de San Francisco, cargo que por su cercanía con una de las órdenes más queridas en la ciudad era proveedor de prestigio al cual sumaba el privilegio de estar exceptuado de servir y contribuir con la milicia. La casa del matrimonio - ubicada en un lugar privilegiado, al lado de la iglesia matriz, frente a la plaza- era de dimensiones considerables, y sus habitaciones se encontraban "edificadas en solar entero todas ellas cubiertas de tejas; que se componen de diez y nuebe Cuartos todos con corredores patios cosina y horno". 34

Una vez viuda, Francisca casó en segundas nupcias con Francisco de Bracamonte, un español que llegó a Santa Fe después de haber pasado por Perú, Chile y Córdoba. ${ }^{35}$ Este hombre devino un personaje muy controversial en la vida política local, y su comportamiento en las alianzas políticas capitulares, antes que sumar apoyos para la familia que había pretendido incorporarlo como parte del proyecto, en distintas oportunidades constituyó un verdadero obstáculo para las pretensiones de la familia Martínez del Monje.

\footnotetext{
XVIIIth cc.), Milano, Franco Angeli Editore, 2012.

32 AGSF, AC, tomo vI, ff.100 a 102; 413v.-416v., 172v.-173v.

${ }^{33}$ AGSF, AC, tomo VI, ff.518v.-520; tomo vII, ff.6o-61.

${ }^{34}$ AGSF, AC, tomo VI, ff.403v.-404.

${ }^{35}$ Luis María Calvo, “Martínez del Monje”, p.62.
}

31 Alejandro A. Damianovich, "Juan José de Lacoizqueta. Gestor del privilegio santafesino del Puerto Preciso", en Revista América n. ${ }^{\circ} 10$, Santa Fe, 1991; Rafael Guerrero Elecalde y Griselda Tarragó, "La certera espacialidad de los vínculos: los Tagle Bracho entre la Montaña, Lima y el Río de la Plata (primera mitad del siglo XVIII)", Prohistoria [online]. vol.18, Rosario, 2012, pp.1-24; Griselda Tarragó, "The long kiss of goodbye: Santa Fe and the conflict over the privilege of puerto preciso (1726-1743)", en Giuseppe de Luca y Gaetano Sabatini (eds.), Growing in the Shadow of an Empire. How Spanish Colonialism Affected Economic Development in Europe and in the World (XVIth- 


\section{b) Juan de Lacoizqueta, el yerno noble}

No obstante los hijos varones, el tercero de los yernos del matrimonio, Juan de Lacoizqueta, segundo marido de María Martínez del Monje, ${ }^{36}$ se convirtió en un engranaje clave en el andamiaje político de la familia. ${ }^{37}$

Este hombre, natural de Legasa (Navarra) era hijo de Juan de Lacoizqueta y María de Hizu. Nació en 1653 y además era noble. ${ }^{38}$ Contrajo matrimonio con María el 12 de diciembre de 1691.

Como militar, dirigió la expedición santafesina de 1704 a Colonia de Sacramento, costeando de su propio patrimonio parte de los gastos de la expedición, lo que le valió el grado militar de maestre de campo que le fue conferido en $1705 .{ }^{39} \mathrm{Se}$ desempeñó como alcalde de primer voto en $1694,{ }^{40}$ y ocupó este cargo más tarde en otras tres oportunidades: durante 1701, 1708, y $1723 .{ }^{41}$ También esgrimió la vara de segundo voto en 1711 y $1712,{ }^{42}$ fue procurador general en $1695,1697^{43}$ y $1708 ;{ }^{44}$ ofició como defensor de menores en 1698, 1709, 1710 y 1711 y en 1708 fue uno de los fiadores (el otro fue Gabriel de Arandia) de Juan José de Ahumada para el oficio de teniente de gobernador, 45 cargo que él mismo ejerció entre 1712 y $1715 .{ }^{46}$

\footnotetext{
36 María se había casado en primeras nupcias con Antonio Pérez el 24 de agosto de 1681. ACM, M, tomo $1642-1715$, f.26

37 ACM, M, tomo 1642-1717, f.41v.

38 Sobre su blasón y los cambios a los que fue sometido más tarde, ver Federico Aldao Ocampo, Genealogía - Hombres de Mayo, Buenos Aires, RIACG, 13, 1961, pp.21.

${ }^{39}$ A. Damianovich, “Juan José de Lacoizqueta”.

${ }^{40}$ AGSF, AC, tomo VI, ff.29-30v.

${ }^{41}$ AGSF, AC, tomo VI, ff.252-254; 500-501, tomo IX, ff.1-2v.

42 AGSF, AC, tomo VI, f.53, tomo VII, f.119.

${ }^{43}$ AGSF, AC, tomo VI, ff.103v.-105.

${ }^{44}$ AGSF, AC, tomo VI, ff.521-522.

${ }^{45}$ AGSF, AC, tomo VI, sesión del 13 de octubre de 1708, ff.276-277.

46 AGSF, AC, tomo VII, ff.117-118 v. Lacoizqueta llegó al oficio de la siguiente manera: el día siguiente de haber asumido el gobierno del Río de la Plata, el visitador Juan José de Mutiloa y Anduesa envió
} 
El oficio de teniente de gobernador transformaba a cualquier agente en una pieza clave más allá del ámbito local: la elección de un hombre de la ciudad por parte del gobernador de Buenos Aires, el prestigio del cual lo revestía esta elección además de investirlo como justicia mayor en la ciudad, jugaba el rol de bisagra o enlace entre el orden político local y el provincial. Como presidente del cabildo, el teniente articulaba las aspiraciones municipales con las decisiones que debían negociarse en la cabecera. Pero el alcance de sus atribuciones no dependía sólo de la normativa sino de la voluntad de los capitulares, que podían ampliarlas, acotarlas o resignificarlas de diversas maneras. Por ende, las relaciones interpersonales del titular del cargo, facilitaban o entorpecían las negociaciones: su gestión podía abrir las puertas a escala de gobernación -aportando información calificada y relaciones más que interesantes para el desarrollo de negocios- 0 entorpecerlas. ${ }^{47}$

En este sentido, Juan de Lacoizqueta se había labrado un bagaje de relaciones bien cuidadas que tenían por contraparte a hombres de gran experiencia política: en 1713, Baltazar García Ros (gobernador interino de Paraguay entre 1705 y 1707) fue testigo del casamiento de una de sus hijas (María Ventura) con José de Sabiñan. ${ }^{48}$ La relación entre estos hombres, pasada por el vínculo ritual en 1713, adquirió brillo inmediato en la percepción de los convecinos cuando en 1714 García Ros fue nombrado gobernador de Buenos Aires.

sendos autos a la ciudad de Santa Fe y a la de Corrientes ordenando el cese de sus respectivos tenientes de gobernador -fieles al gobierno visitado- otorgando la calidad de justicia mayor a quienes revistaban en cada cabildo como alcaldes de primer voto. Así fue que cesó Juan Joseph de Ahumada, pero Antonio de Vera de Mendoza se vio imposibilitado de asumir y por este motivo su lugar fue ocupado por Juan de Lacoizqueta, que era alcalde de segundo voto. AGSF, AC, tomo VII, ff.125v.126, 256-257. Según Birocco, la intervención del visitador Mutiloa representaba un intento de poner fin al "poder autocrático que habían ejercido los gobernadores en el Río de la Plata entre el último cuarto del siglo XVII y la primera década del siglo XVIII [...]", Carlos María Birocco, "La pesquisa de Mutiloa en Buenos Aires. Conformación de facciones y lucha por el poder en el cabildo porteño (1700-1715)", en Ma. Paula Polimene (coord.), Autoridades y prácticas judiciales en el Antiguo Régimen. Problemas jurisdiccionales en el Río de la Plata, Córdoba, Tucumán, Cuyo y Chile, Rosario, Prohistoria, 2011, p.34.

47 Darío G. Barriera, "Resistir al Teniente con la letra del Rey: la conflictiva relación del Cabildo de Santa Fe con la Gobernación del Río de la Plata, años 1620”, en Gabriela Dalla-Corte, Pilar GarcíaJordán et al (coords.), X Encuentro Debate América Latina Ayer y Hoy: homogeneidad, diferencia y exclusión en América, Barcelona, Universidad de Barcelona, 2006, pp.65-72.

48 ACM, M, tomo 1642-1717, f.117v. 
El camino de los hijos: a la justicia por la venalidad

a) Ignacio Martínez del Monje, uno de los hijos varones de Francisco, compró el oficio de alférez real perpetuo para Santa Fe en 1713, y lo ejerció hasta su muerte, acaecida en $1730 .{ }^{49} \mathrm{El}$ fiador de dicha compra fue su cuñado, Pedro de Urizar. ${ }^{50}$

Sucedió en el cargo a Francisco Izquierdo que había comprado este oficio y el de regidor en Potosí en 1699. ${ }^{51}$ Como se relató más arriba, Izquierdo presidía el cabildo cuando su padre apeló la elección del cargo de alcalde de primer voto en 1687. Aquel enfrentamiento no parece haber tenido secuelas negativas. Poco antes de morir, Izquierdo renunció el cargo de Alférez a favor de Ignacio Martínez del Monje, pero la renuncia no tuvo efecto debido a que no se cumplieron los plazos estipulados por la normativa para las renuncias de oficios y el cargo volvió al patrimonio regio. Por otra parte, Francisco Izquierdo había nombrado sus albaceas testamentario a Juan de Lacoizqueta, cuñado de Ignacio. ${ }^{52}$ Estas proximidades sugieren que, para estos años, el exteniente y exalférez Izquierdo notoriamente formaba parte de la configuración política del grupo.

Ignacio Martínez del Monje compró el oficio de alférez en 1200 pesos. Además de su importancia en el aspecto ceremonial -representaba la lealtad a la monarquía portando el Real Estandarte en las ceremonias de mayor importancia- la clave era su posición en las precedencias de sillas capitulares: era el primero para reemplazar a los alcaldes en caso de ausencia o renuncia.

El portador del estandarte no era un lego ni un advenedizo. Tenía antecedentes en la portación de varas: Ignacio había sido electo como alcalde criminal en 1705 y 1709.53 Pero la inmediatez con la cual intentó hacer valer uno de los privilegios que comportaba su oficio -el de reemplazar al alcalde de primer voto- permite inferir que la adquisición de este oficio no tenía otro propósito que el de acceder a la administración de la justicia.

\footnotetext{
${ }^{49}$ AGSF, AC, tomo VII, ff.156v.-157.

${ }^{50}$ AGSF, AC, legajo 22, ff.974-1013.

${ }^{51}$ AGSF, AC, tomo VI, ff.221v.-223.

${ }^{52}$ AGSF, AC, tomo VI, ff.276-277.

${ }^{53}$ AGSF, AC, tomo VI, ff.393-394, y 523-524, respectivamente.
} 
La urgencia de Ignacio Martínez del Monje por hacer valer sus prerrogativas se manifestó de inmediato: su título fue obedecido el 4 de noviembre de 1713, cinco días después el regidor propietario Francisco de Vera Mujica le entregó el estandarte real y el 13 de febrero de 1714, ante la ausencia del alcalde Melchor de Gaete (quien había ido a la Otra banda del Paraná) solicitó ejercer la alcaldía de primer voto interinamente por ser una regalía de su oficio. ${ }^{54} \mathrm{En}$ las elecciones de 1715, los candidatos que el alférez propuso para alcaldes de primer y segundo voto perdieron a manos de los propuestos por el regidor propietario Francisco de Vera Mujica. Esta elección, ratificada por el teniente de gobernador Martín de Barúa, marcó el inicio de una contienda interpersonal que expresaba un conflicto entre familias y adquirió diversos matices. ${ }^{55}$ Durante el mismo año exigió reemplazar al alcalde Andrés López Pintado aunque este estaba sólo a cuatro leguas de la ciudad. ${ }^{56}$ En 1718 y $1725^{57}$ se hizo cargo interinamente de la alcaldía de primer voto durante ausencias breves de los alcaldes. Accedió a la segunda vara a través de un interinato en 1718 y $1721^{58}$ y a la primera en 1722 -aunque en esta ocasión por iniciativa del propio gobernador Zavala y en reconocimiento de sus servicios ${ }^{-59}$ por lo cual podemos decir que de algún modo se especializó en la función judicial. Ignacio Martínez del Monje convirtió el oficio de alférez en un modo más o menos elegante pero sobre todo legal, venal y legítimo para acceder a la función judicial ordinaria, ligada a un oficio no vendible. El oficio de alférez podía venderse o legarse a través del mecanismo de la "renuncia", por lo cual significaba además una inversión que podía recuperarse después de haber usufructuado algunos de los privilegios que otorgaba.

\footnotetext{
${ }^{54}$ AGSF, AC, tomo VI, ff.157-158, 170.

55 M. Celeste Forconi, "Interesse em conflito entre a prática e a legalidade: o exercício do poder político em Santa Fé (século XVIII)", em Métis: história \& cultura, Universidade de Caxias do Sul/Centro de Ciências Humanas/Área de História, Caxias do Sul- Brasil vol.XIII, n. ${ }^{\circ}$ 25, 2014, pp.59-83.

56 AGSF, AC, tomo VII, ff.186v y 187, sesión del 30 de julio.

${ }^{57}$ AGSF, AC, tomo VII, ff.395v.-396, y tomo IX, ff.241v.-242, respectivamente.

58 AGSF, AC, tomo VIII, ff.271v-272; 381 y v., respectivamente.

${ }^{59}$ AGSF, AC, tomo VIII, ff.297-298. Sin embargo, el 18 de enero el cabildo recibió una nota de Zavala por la cual aprobaba la elección anual con excepción del oficio del Alcalde ordinario de $1^{\mathrm{o}}$ voto, que debía ser nuevamente electo, por oponerse a la Ley $8^{\circ}$, título $3^{\circ}$, libro $5^{\circ}$ de la Recopilación sobre que deben ser electos como alcaldes los que fueran vecinos de la ciudad. Por este motivo se convocó nuevamente a elección para ese oficio siendo electo Ignacio Martínez del Monje, AGSF, AC, tomo VIII, ff.295-295v.
} 
El 30 de abril de 1725, Francisco de Bracamonte informó al cabildo que había embargado los oficios de alférez real y alcalde provincial, por lo que Ignacio Martínez del Monje debió entregar el estandarte real a instancias de su conflictivo cuñado, abriéndose un periodo de variopintos conflictos que analizamos más adelante. Ignacio falleció en 1730.

b) Miguel Martínez del Monje, hermano de Ignacio, fue uno de los miembros más activos del cabildo santafesino durante el segundo cuarto del siglo XviII, desempeñando variadas funciones. Puede constatarse que antes de iniciar su actuación política, fue el continuador de los negocios yerbateros de su padre en el Paraguay: allí se casó con María de Rojas Aranda, hija y nieta de encomenderos. Su suegro, el Alférez Isidro de Rojas Aranda -hijo del Capitán Alonso de Rojas Aranda- era titular no de una sino de tres encomiendas que habían sido dadas por dos vidas en los años 1630 (indios reducidos en el pueblo de los Altos), 1638 (de originarios, otorgada por don Pedro de Lugo y Navarra) y 1652 -otra de originarios por vía de agregación, concedida a su padre por el Licenciado Andrés Garavito de León. ${ }^{60}$ Los vínculos con la aristocracia de mérito paraguaya fortalecían la posición comercial revistiéndola con prestigio y alcurnia, imprescindible para quienes no podían acreditar dos generaciones en el área. Su mujer, con la cual hubo tres hijos (Miguel, Juan Ignacio y Franco Fermín), aportó al matrimonio 11080 pesos de dote en especies, mientras que reconoce que su aporte de capital fue de 5.000 pesos de plata. Miguel enviudó en Paraguay y en ese momento volvió a Santa Fe "por el río [...]", donde afirma haber perdido la mayor parte de su hacienda -ventilando en su testamento que lo aclara para no tener litigio con los herederos. ${ }^{61}$

Miguel alcanzó el grado militar de capitán y en 1724 fue electo para el oficio de alcalde de segundo voto. ${ }^{62}$ En 1725 accedió a una regiduría perpetua en virtud de la renuncia que Melchor de Gaete hizo en su favor. ${ }^{63}$ En 1728 fue elegido alférez real por votación de los alcaldes ordinarios y el mismo año, fue designado para re-

\footnotetext{
${ }^{60}$ Ernesto A.Spangerberg, "Censo de encomenderos del Paraguay de 1674”, en Genealogía n⿳0 32 , Buenos Aires, 1992, p.458.

${ }^{61}$ DEEC, SF, EP, tomo XXVI, exp.215, ff.64-79, testamento de Miguel Martínez del Monje.

${ }^{62}$ AGSF, AC, tomo IX, ff.101-103v.

${ }^{63}$ AGSF, AC, tomo IX, ff.253v.-256.
} 
emplazar durante su ausencia al alcalde de la hermandad Joseph Márquez Montiel. ${ }^{64}$ En 1730 fue electo alcalde de primer voto. ${ }^{65}$ Entre los electores (el cabildo saliente) se contaban un sobrino político (Manuel Maciel, ${ }^{66}$ alcalde de segundo voto) y su hermano Ignacio como alférez real.

Desde 1730 hasta 1740, Miguel ocupó la mayoría de las veces el cargo de fiel ejecutor, oficio ligado a la recaudación de derechos de romana, licencias, cumplimiento en las disposiciones sobre pesos y medidas por parte de pulperos y comerciantes, etc. En 1737 fue nombrado tesorero de la ciudad, pero rechazó el cargo aduciendo que estaba enfermo. ${ }^{67}$ Este conjunto debe completarse con las numerosas oportunidades en que se desempeñó interinamente como alcalde de $1^{0}$ o de $2^{\circ}$ voto ante la ausencia de los titulares. En 1734, 1742, 1746 y $1748^{68}$ asumió interinamente como alcalde de primer voto y, en 1731, 1733, 1738, 1741, 1744, 1745 y 1747, como alcalde de segundo voto. ${ }^{69}$ Éstos son algunos de los años en que ocupó las alcaldías de forma interina.

Tanto Ignacio como Miguel pueden considerarse miembros especializados en la administración de justicia ordinaria de la ciudad: entre ambos hermanos, portaron la vara en 30 (treinta) ocasiones en un lapso de apenas 43 años (1705, la primera actuación de Ignacio, 1748, la última de Miguel). Sin embargo, Miguel sumó a esta especialización la proximidad con la administración del dinero del común como apoderado del derecho de Romana y como recaudador de propios siempre estuvo en contacto con los dineros de la ciudad.70

Esta fuerte presencia dentro de la institución capitular, como se adelantó, no fue plañidera y sin disputas. En las elecciones de 1730 Miguel fue elegido alcalde de

\footnotetext{
64 AGSF, AC, Carpeta n. ${ }^{\circ} 14 \mathrm{~A}$, ff.4-4v., 76-77v.
}

${ }^{65} \mathrm{AGSF}, \mathrm{AC}$, Carpeta n. ${ }^{\circ} 14 \mathrm{C}, \mathrm{ff} .185-187 \mathrm{v}$.

${ }^{66}$ Manuel Maciel estaba casado con Rosa de Lacoizqueta, que era su sobrina por ser hija de María Martínez del Monje y de Juan de Lacoizqueta. Luis María Calvo, "Lacoizqueta”, en Revista Genealogía n. ${ }^{0}$ 8, Buenos Aires, 1979.

${ }^{67}$ AGSF, AC, tomo X, ff.353v.-356v.

${ }^{68}$ AGSF, AC, tomo X, ff.190-192; tomo XI, ff.68-69v., 326-328, 420-421v.

${ }^{69}$ AGSF, AC, tomo X, ff.6o-61, 135-137, 408 v.-410; tomo XI, ff.14-16, 248-250, 251-253, 393-394v.

70 Testamento de Miguel Martínez del Monje, otorgado en Santa Fe el 25 de septiembre de 1749. DEEC, SF, EP, tomo XXVI, exp.215, ff.64-79. 
primer voto por la mayoría de los capitulares, pero Esteban Marcos de Mendoza, el alcalde saliente, pidió al gobernador la nulidad de la elección, no arguyendo que lo eligieron sus parientes sino que era regidor propietario. Aunque el gobernador hizo lugar al pedido de anulación, Miguel Martínez del Monje y Juan de Zevallos ambos regidores propietarios- apelaron su despacho argumentando que iba en contra de una costumbre inmemorial consagrada por Real Provisión de 1715 que ya había autorizado a los regidores propietarios a ser electos como alcaldes ordinarios, estimando además que la descontinuación de dicho privilegio (regalía en el documento) era un agravio a la ciudad. ${ }^{71}$

El gobernador confirmó la elección de Pedro de Zavala para el oficio de alcalde de primer voto -"hecha por la menor parte de los vocales"- no obstante lo cual el cabildo inició una apelación por la decisión del teniente de gobernador Baltazar García Ros y dos años mas tarde (en mayo de 1732) llegó la copia de la Real Provisión que anulaba el auto del gobernador que en su hora había también anulado la elección de Miguel Martínez como alcalde de primer voto y autorizaba al cabildo de Santa Fe a elegir a sus regidores propietarios para el ejercicio de las alcaldías ordinarias en virtud de la Real Provisión de 1715 y de la costumbre de la ciudad. ${ }^{72}$

El conflicto muestra que según los intereses en disputa podía conseguirse circunstancialmente el apoyo de alguien de la coalición contraria: por eso cuando se lesionaba una prerrogativa compartida, hombres cuya relación podía caracterizarse como una enemistad manifiesta (Miguel y Juan de Zevallos, enemigos públicos) podían alinearse defendiendo la misma causa, en este caso, la vigencia de la Real Provisión que permitía la elección de regidores propietarios -ambos lo erancomo alcaldes ordinarios.

Este episodio, además, exige una comparación con el protagonizado quince años antes por su hermano, Ignacio Martínez del Monje, ya que en la votación cadañera de 1715,73 Ignacio había objetado la elección de las alcaldías porque Andrés López Pintado -electo alcalde de primer voto- era regidor propietario y el alcalde

\footnotetext{
${ }^{71}$ AGSF, AC, Carpeta n. ${ }^{\circ} 14$ C, ff.196-198.

72 AGSF, AC, tomo X, ff.96 y v.

${ }^{73}$ AGSF, AC, tomo VII, ff.246-250v.
} 
segundo, Francisco de Ziburu, tenía una causa pendiente en la Real Audiencia. ${ }^{74}$ En aquella oportunidad, Ignacio utilizó la misma argumentación empleada para pretender obstaculizar la de su hermano en 1730. Pero Ignacio Martínez del Monje había utilizado esa argumentación apoyándose en otra pieza jurídica, de segundo orden, en este caso un acto de buen gobierno: citó una nota que el gobernador rioplatense había dirigido al cabildo santafesino el 1 de febrero de 1714, "[...] previniendo al cuerpo que en adelante los cargos no sean cubiertos con capitulares propietarios". Si bien el cabildo respondió que dicha reconvención iba contra la costumbre, ${ }^{75}$ Ignacio Martínez del Monje insistió en la utilización de esa nota, pieza disponible del derecho local -aunque de menor peso que las leyes de indias y que las reales provisiones, un bando o una nota del gobernador podían considerarse, efectivamente, una pieza legal-. Lo que jugaba en su contra, no obstante, no es un detalle menor: el escribano del cabildo certificó que, cuando el cuerpo capitular se opuso al gobernador en lo que concernía a innovar en este terreno, Ignacio estaba presente [...]". ${ }^{76}$ La ratificación del derecho de los regidores por una Real Provisión en 1715, posterior a y seguramente consecuencia del planteo de Ignacio, puede considerarse un ladrillo en la edificación de lo inmemorial que se invocó en 1730.

Por último, en 1746, el fallecimiento del alcalde de primer voto Luis Rivero Raposo y su reemplazo por Miguel Martínez del Monje desató otro conflicto: ${ }^{77}$ el 30 de junio ${ }^{78}$ el acuerdo trató una petición de Antonio Candioti y Mujica que requería al gobernador el ejercicio de la vacante vara de alcalde primero para su suegro, Juan de Zeballos. El teniente contestó que "[...] la solicitud es anticipada por cuanto el Cab. de S. Fe no se ha negado, y que, a falta de Alférez Real, corresponde al Regidor más antiguo entrar en el depósito de la vara de Alcalde" ${ }^{79}$ En estas circunstancias, Miguel -titular del oficio de alférez que de todos modos no estaba ejerciendo activamente- decidió arrendarlo con el solo fin de sacar del medio a

\footnotetext{
${ }^{74}$ Las Leyes de Indias (libro V, título 3) especificaban como requisito no tener causas judiciales pendientes.

${ }^{75}$ AGSF, AC, tomo VII, ff.168v.-169v.

76 AGSF, AC, tomo VII, ff.250v.-251.

77 AGSF, AC, tomo XI, ff.370-371.

${ }^{78}$ AGSF, AC, tomo XI, ff.376-377.

${ }^{79}$ AGSF, AC, tomo XI, ff.378-379.
} 
Juan de Zevallos y asegurar para su grupo los sucesivos reemplazos en las alcaldía. El modo elegido fue el de otorgar un poder a su sobrino, Pedro Florentino de Urízar, para que hiciera postura en el arrendamiento del oficio de alférez real. En la postura quedaron explícitos tanto el precio $-\$ 450$ por tres años, con un canon de $\$ 150$ anuales por cada uno que quisiera proseguirse el arrendamiento- como los motivos. ${ }^{80}$

Como puede verse, no hay aquí ninguna tensión entre normas y prácticas, sino constancia de que un gran dominio de la esgrima política. Uno u otro fragmento de normativa eran convocados a la hora de elaborar el argumento. Y entre piezas menores, como en el caso que relatamos, no era infrecuente que terminara por imponerse una nota del gobernador o la adquisición de un privilegio reciente travestido en costumbre inmemorial, entronización objetiva de la obtención del apoyo político de una mayoría coyuntural. 81

La manifestación del funcionamiento de este juego con usos aparentemente opuestos por parte del mismo grupo (decimos aparentemente porque aunque los argumentos son opuestos el modo de entender cómo era el juego es el mismo) es una de las respuestas contundentes a la pregunta sobre los motivos por los cuales algunos sujetos trabajaban tan duramente para que su coalición que consiguiera supremacía en un cabildo año a año. Trabajar e invertir: porque esto también permite comprender por qué motivos se invertía dinero particularmente en la compra de algunos oficios o dotes crecidas en los casamientos.

Si bien la relación entre las políticas de la monarquía hispánica en expansión y los agentes que encarnaron la colonización tiene segmentos de felices coincidencias, también presentó puntos de tensión. ${ }^{82}$ Uno de ellos giró en torno a la provi-

\footnotetext{
${ }^{80}$ Puesto que el postulante no se privó de aseverar que lo arrendaría “[...] con la expresa, y precisa Condición de que haya de gozar de todos los privilegios, Ejercicios, Regalías, preeminencias e inmunidades anexas y pertenecientes a ese oficio, según y como le an obtenido y gozado los Alférez Reales propietarios, y en los casos de muerte, ausencia u otro impedimento decualesquiera de los Alcaldes hordinario haya de recaer la vara, y administración a la Rl Justi. ${ }^{a}$ en dicha mi parte como también, se le haya deponer en posesión de la que obtiene al pres.te por despósito el Regidor más antiguo por muerte de Dn Luis Rivero Raposo, por ser conforme al privilegio de dicho oficio de Alférez Real.” AGSF, AC, tomo VI, f.818.

${ }^{81}$ Una primera interpretación sobre este tema en Darío G. Barriera, "Un rostro local de la Monarquía Hispánica: justicia y equipamiento político del territorio al sureste de la Real Audiencia de Charcas, siglos XVI y XVII", in Colonial Latin American Historical Review vol.15, n. ${ }^{\circ}$, Albuquerque, New Mexico University, 2006, pp.377-418.
}

82 D. G. Barriera, “Un rostro local”. 
sión de encomiendas, prebendas y oficios. Inicialmente otorgados por merced real, quienes los recibieron como sus primeros titulares desarrollaron diferentes iniciativas (a escala de todo el imperio) para que fueran en principio vitalicios, luego hereditarios, en fin, en convertirlos en una propiedad que formara parte de su patrimonio -por eso se habla justamente de "patrimonialización" de los oficios. De este modo, su significado de función y carga pública fue desplazado - primero en Castilla e inmediatamente después en las provincias americanas de la monarquía ibérica- por el de un preciado bien que permitía acumular, a un tiempo, dinero, prestigio y poder político. De modo que el fenómeno del comercio de los oficios públicos fue una práctica de los particulares que la Monarquía debió reconocer y a la que luego dedicó una organización sistemática y la convirtió en una de las principales fuentes de ingresos, sobre todo durante el gobierno de los Austrias. ${ }^{83}$ Las crecientes dificultades financieras que enfrentaba la Corona sirvieron de acicate para que Felipe II autorizara la venta de ciertos cargos. Poco a poco, la lista de los oficios venales fue ampliándose, no obstante lo cual siempre se pusieron múltiples reparos para integrar a la misma cualquier oficio que tuviera incumbencia jurisdiccional. ${ }^{84}$

\section{Cuñados malavenidos}

La enemistad entre Francisco de Bracamonte y sus cuñados parece desprenderse de una disputa por los bienes del matrimonio a la muerte de Francisca (muy probablemente en 1713) quien no había dejado descendencia. Por este motivo, el 13 de enero de 1714 su madre Isabel de Pessoa presentó el reclamo de los bienes que integraban su dote ${ }^{85}$ y Bracamonte se negó a entregárselos, aduciendo que estaban

\footnotetext{
${ }^{83}$ Francisco Tomás y Valiente, La venta de oficios en Indias (1492-1606), Madrid, Instituto de Estudios Administrativos, 1972; Francisco Andújar Castillo, Necesidad y venalidad. España e Indias, 1704-1711, Madrid, Centro de Estudios Políticos y Constitucionales, 2008; Antonio Álvarez-Ossorio Alvariño, "La venta de magistraturas en el reino de Nápoles durante los reinados de Carlos II y Felipe V", en Chronica Nova n $^{0} 33$, Granada, Universidad de Granada, 2007, pp.57-94.

84 Irene Rodríguez, Celeste Forconi y Daniela Foglia, "La venta de cargos y la administración de justicia en el siglo XVIII", en Darío Barriera (dir.), Economía y Sociedad (siglo XVI a XVIII), Nueva Historia de Santa Fe, Rosario, La Capital, 2006. Roberta Stumpf y Nandini Chaturvedula (orgs.), Cargos e ofícios nas Monarquías Ibéricas: provimento, controlo e venalidade (séculos XVII e XVIII), Lisboa, CHAM, 2012.

85 DEEC, SF, EC, tomo 21, leg.93, f.114-137, Isabel de Pessoa con Francisco Bracamonte sobre herencia (1714).
} 
embargados por la Real Hacienda a causa de deudas contraídas por Juan de Rezola, primer marido de Francisca, también fallecido.

En esta ocasión, el control que la familia tenía sobre las varas de la justicia podía ser tan útil como incómodo: la negativa de Bracamonte a integrar la dote disparó una petición de su suegra ante la justicia ordinaria de la ciudad en la cual solicitaba la realización de un inventario y entrega de los bienes que le correspondían como heredera de su hija. El argumento de Isabel se apoyaba en que era "[...] publico, y notorio q el empleo q fue a hazer al Reino de Chile, de donde resultaron los generos de q armo su tienda; lo hizo con vienes y plata de dha difunta; y caso negado q no fueren en este caso, no se le puede quitar el dro, q a ellos tiene de mitad de ganansiales por aver sido adquiridos en el tpo de su matrim.o [...]". ${ }^{86}$ La presentación de Isabel, a la defensiva, apuntaba a salvar al menos el 50\% ("la mitad de gananciales"). La causa fue llevada adelante por el alcalde de segundo voto, Pedro de Arizmendi, y se nombraron además - por sorteo entre cuatro- a otros dos jueces acompañantes, Juan de Aguilera y Gabriel García Ramírez. ${ }^{87}$

Ese fue el momento en el cual Bracamonte pasó de la movilidad física del comercio a otra que combinaba bien con esta: la acción política. Esta decisión estuvo probablemente orientada en que percibió (correctamente) que desde esta arena podría refrendar sus capacidades para defender lo que tenía frente a las (legítimas) pretensiones de la familia de su esposa fallecida. Para hacerlo, no obstante, no alcanzaba con su sola voluntad, y debía insertarse en una configuración que lo aceptara y para eso era preciso componer algunos acuerdos sobre mínimos intereses comunes.

Consiguió el oficio en enero de 1716: Andrés López Pintado renunció su regiduría perpetua a favor de Francisco de Bracamonte. No tenemos el monto de la compra, pero sí sabemos que pudo ejercerlo recién a partir de febrero, cuando se recibió su título en el cabildo. Ese mismo año ocupó el oficio de alcalde de segundo voto y presentó su título de tesorero de la Real Hacienda en Santa Fe, oficio que

\footnotetext{
${ }^{86}$ DEEC, SF, EC, tomo 21, leg.93, f.129.

${ }^{87}$ Ellos remitieron los autos al gobernador para su vista y Joseph Martínez del Monje viajó a Buenos Aires representado a su madre. DEEC, SF, EC, tomo21, leg.93, Isabel de Pessoa con Fco. Bracamonte sobre herencia, ff.127, 131.
} 
ejerció desde 1716 hasta su muerte en 1737.88 López Pintado la había pagado 325 pesos. 89

El deterioro de la relación entre Bracamonte y sus cuñados no se hizo esperar: en julio de 1716 Ignacio Martínez del Monje (en calidad de alférez) presentó al Cuerpo dos Provisiones Reales que ordenaban la precedencia en la sucesión y la preferencia de asiento del alférez real respecto del tesorero -cargo que en ese momento ocupaba Bracamonte..$^{90} \mathrm{El}$ asunto era aparentemente una cuestión de etiqueta: Bracamonte, un recién llegado y traidor a la familia, se imponía a su cuñado en actos públicos y religiosos, lo cual era socialmente insoportable. Durante la celebración de San Ignacio, la disputa por la silla dentro de la iglesia de los padres jesuitas, dio lugar a un incidente que exigió la intervención del teniente de gobernador, quien exigió a ambos que saliesen "[...] de la yglesia en cuidasion del escandalo. O tomasen el asiento que an acostumbrado [...]”. ${ }^{91}$

El Cuerpo resolvió no innovar la costumbre y autorizó a las partes a reclamar sus derechos ante el tribunal competente. Al año siguiente, Ignacio presentó otra Real Provisión otorgada por la Real Audiencia de la Plata, fechada el 31 de octubre de 1716, que ordenaba que su oficio debía tener asiento delante del teniente de oficiales reales (tesorero) en las procesiones y concurrencias públicas. ${ }^{92}$

La institución de una costumbre es consustancial con la dinámica del ritual, caracterizada por su "carácter repetitivo, formal, tradicional e invariable". ${ }^{93}$ Este

\footnotetext{
88 AGSF, AC, tomo VII, ff.261-266, 209, 274-277, 365-367, respectivamente.

${ }^{89}$ AGSF, AC, tomo VII, f.261.

90 “[...] se presento una Rl. Provicion de su alteza pr. Parte del Alferez Rl. Dn. Ignacio del Monxe, en que su alteza manda que el dho Alferez Rl. Propietario aya de levantar la bara de la Real Justicia siempre que acaesca, muerte, ausencia de qualesquiera de los dos alcaldes ordinarios [...] y otra en que manda su alteza que prefiera en el asiento en los actos y concurrencias publicas al then.te de oficiales Reales [...]” AGSF, AC, tomo VII, ff.286-287.

${ }^{91}$ AGSF, AC, tomo vII, ff.287-289v.

92 AGSF, AC, tomo VII, ff.307v.-308.

${ }^{93}$ Silvina Smietniansky, Ritual, tiempo y poder. Una aproximación antropológica a las instituciones del gobierno colonial: Gobernación del Tucumán, siglos XVII y XVIII, Rosario, Prohistoria Ediciones, 2013. Un estudio clásico, Juan Carlos Garavaglia, "El teatro del poder: Ceremonias, tensiones y conflictos en el Estado Colonial”, en Boletín del Instituto Dr. Emilio Ravignani n. ${ }^{\circ} 14$, Buenos Aires, 1996, pp. 7-30.
} 
conflicto, que expresa una disputa por alguno de los elementos claves que componían el inventario de los atributos del poder político y del prestigio social en aquella sociedad, manifestaba otro aspecto de las disputas por la primacía en un ámbito de poder político -el de la visibilidad de la autoridad para todos los que están sometidos a ella- y aporta de lleno a los procesos de construcción de la autoridad.

Hace muchos años que Georges Balandier señaló la importancia de "[...] la transposición, por la producción de imágenes, por la manipulación de símbolos y su ordenamiento en un cuadro ceremonial [...]" en el marco de la comprensión de las luchas por el poder político. ${ }^{94} \mathrm{El}$ protocolo y el ceremonial manifestaban un orden social cuya jerarquía era más sencilla de transmitir dramática que verbalmente: las fiestas públicas desplegaban significados que actualizaban el diálogo y discutían las calidades en juego entre quienes conformaban el sujeto de la enunciación del mensaje como así también comunicaban el status quo (una foto del estado del arte de dicha disputa) para un público que, aunque lego en la materia, no era insensible a la comprensión de la dimensión política que estos mensajes teatralizados conllevaban ${ }^{95}$-y por esto mismo la importancia ya señalada del oficio de alférez, que al implicar la portación del pendón Regio simbolizaba la figura del Rey. ${ }^{96}$

Durante la asunción de Bracamonte como tesorero, el Cuerpo invocó la Recopilación de las Leyes de Indias, de las cuales resultaba la incompatibilidad entre

\footnotetext{
94 "Estas operaciones [agregó el antropólogo] se llevan a cabo de acuerdo con modelos variables y combinados de presentación de la sociedad y de legitimación de las posiciones gobernantes". Georges Balandier, El poder en escenas. De la representación del poder al poder de la representación, Barcelona, Paidós, 1994, pp.17-18.

${ }^{95}$ Aunque no se ignora el valor seminal de las aportaciones de M. Bajtin y los Ozour, remitimos a los trabajos más recientes de Pablo Ortemberg (dir.), El origen de las fiestas patrias Hispanoamérica en la era de las independencias, Rosario, Prohistoria Ediciones, 2013, y Pablo Fucé, El poder de lo efimero. Historia del ceremonial español en Montevideo (1730-1808), Montevideo, Linardi y Risso, 2014.

${ }^{96}$ La relevancia de símbolos como este se agigantaba de manera directamente proporcional con la distancia física que separaba a el lugar de su portación de la residencia permanente del rey. Víctor Mínguez, Los reyes distantes. Imágenes del poder en el México virreinal, Castelló de la Plana, Universitat Jaume I, 1995. Sobre la distancia y su implicancia en relaciones judiciales, Darío G. Barriera, "Entre el retrato jurídico y la experiencia en el territorio. Una reflexión sobre la función distancia a partir de las normas de los Habsburgo sobre las sociabilidades locales de los oidores americanos", en Caravelle n. ${ }^{\circ}$ 101, Toulouse, 2013, pp.133-154. En el marco local, la relación entre este oficio y la autoridad regia asignaba evidentemente un atributo de prestigio y reconocía una posición social encumbrada Felipe Justo Cervera, "Nepotismo y Economía en Santa Fe Siglos XVII a XX", en Revista de la Junta Provincial de Estudios Históricos de Santa Fe n. ${ }^{\circ} \mathrm{LXIV}$, Santa Fe, 2004.
} 
la titularidad de la función de tesorero real con el ejercicio de los oficios de regidor o alcalde -la misma resultaba de pertenecer la primera a la órbita de la administración de la monarquía y la segunda a los intereses corporativos de la ciudad. En consecuencia, Bracamonte renunció al oficio de alcalde de segundo voto y la vara pasó a manos de su cuñado, el alférez real Ignacio Martínez del Monje, pequeño triunfo para los "más leales" de la Casa. ${ }^{97}$

Pero la revancha es un plato que se sirve frío: Ignacio Martínez del Monje se constituyó en fiador del arrendamiento de la alcabala de la ciudad por $\$ 1600^{98}$ y el 7 de diciembre, Francisco de Bracamonte, haciendo uso de sus funciones como tesorero real, ejecutó a los fiadores de porque la ciudad no había cumplido con el pago correspondiente..$^{99}$

El 30 de abril de 1725, Bracamonte informó al cabildo que, cumpliendo una orden superior -provenía del Tesorero Real y del Teniente de Gobernador- había embargado los oficios de alférez real y el de alcalde provincial desempañado por Antonio Márquez Montiel, y solicitó que Ignacio Martínez del Monje entregara el estandarte real. ${ }^{100} \mathrm{El} 2$ de mayo, Juan José de Lacoizqueta -sobrino de Ignacio y yerno de Antonio Márquez Montiel- presentó una petición en nombre de ambos: durante el acuerdo, se mencionó que los acusados "[...] fueron buscados con gente armada, que un día antes la vecindad 'se hallaba horrorizada' por las voces que corrieron y que no se publicó bando ni orden sobre el asunto [...]”. 101

Medidas de este tipo -entre otras que apuntaban en la misma direcciónperseguían deteriorar la calidad (la buena fama) de las personas acusadas, por lo cual los autos contra de Ignacio Martínez del Monje y Antonio Márquez Montiel fueron elevados al gobernador. Pero la resolución -aunque positiva para los acusados- llegó cuatro años más tarde, a través de una Real Provisión que ordenaba dejar libres y en el uso de sus oficios a los acusados: ${ }^{102}$ durante ese tiempo, Bracamon-

\footnotetext{
${ }^{97}$ AGSF, AC, tomo VII, ff.292-295.

${ }^{98}$ AGSF, AC, tomo VII, ff.303v.-305.

${ }^{99}$ AGSF, AC, tomo VII, ff.305v.-307.

100 AGSF, AC, tomo IX, ff.245-246.

101 AGSF, AC, tomo IX, ff.246v.-248.

102 AGSF, AC, Carpeta n. ${ }^{\circ} 14$ “B” 74, ff.129-133v.
} 
te había logrado obstaculizar a Ignacio el acceso a las varas de Justicia y, por ello, obtuvo una victoria política cuya duración, en su contexto, no es para nada despreciable.

Durante ese lapso Bracamonte fue atacado tenazmente por los Monje: el 29 de agosto de 1727, el alcalde primero Joseph Márquez Montiel lo denunció por ejecutar el destierro de un solo hombre "[...] con estrepitoso Ruido y terror de toda la vecindad [...]". En la misma sesión se expuso que el Tesorero tenía a su servicio el destacamento y el tercio de Corrientes y que hacía uso de esos soldados, destinados al resguardo de la frontera indígena, sin que el teniente de gobernador tuviera noticia de esto. El alcalde retrató a este hombre como ensoberbecido "[...] suponiéndose con la fuersa de soldados ministro sin superior que pueda corregir sus excesos [...]" y pidió al teniente Francisco de Vera Mujica que, en su calidad de justicia mayor, frenara los desbordes de un hombre que "[...] aun estado excomulgado [...]" impide de este modo la "administración de justicia" y ofrende a los ministros reales y la real jurisdicción. ${ }^{103}$ El cabildo y el teniente de gobernador remitieron al gobernador testimonio del acuerdo y le solicitaron que pusiera freno a la actuación de Francisco de Bracamonte, "hombre tan violento como ruidoso y soberbio", cuyos procedimientos han causado "que el vulgo se persuade a que es presidente de este lugar”. 104

Francisco Bracamonte murió en febrero de 1737, excomulgado por uno de los Monje, sin haber dejado hijos y "sin habla, privado de todos los sentidos corporales”. ${ }^{105}$ La escritura de esta línea en el registro del cabildo induce a especular cuánto había significado para aquellos capitulares el habla del difunto.

\section{El hijo de Ana}

Pedro Florentino de Urizar, hijo de Pedro de Urizar y Ana Martínez del Monje fue otro de los miembros de la familia que se especializó en el ejercicio judicial, desem-

\footnotetext{
${ }^{103}$ AGSF, AC, tomo IX, ff.404v.-408.

${ }^{104}$ AGSF, AC, tomo IX, ff.408 y v.

105 AGSF, AC, tomo $\mathrm{x}$, ff.348-351v.
} 
peñándose como alcalde de primer y segundo voto. ${ }^{106}$ Llegó a este oficio algunas veces por elección y otras por reemplazo, cumpliendo interinatos. Además, actuó como apoderado de algunos miembros de su familia. ${ }^{107}$

Este personaje fue de suma importancia por su papel de bisagra con los Vera Mujica, ya que contrajo matrimonio con dos mujeres de dicha familia -el 28 de octubre de 1731, con Doña Antonia de Vera Mújica y, después de enviudar, con la hermana de su primera esposa, María Josefa de Vera Mújica, el 17 de agosto de 1756-108 ambas hijas de Francisco de Vera Mújica y Luisa Salguero de Torres Cabrera. Aunque participó escasamente en los movimientos comerciales de la familia, Pedro Florentino fue un verdadero broker ${ }^{109}$ y, en materia de funciones políticas, fungió como el recambio siempre disponible (y aceptable por todos) ante las reiteradas ausencias que, por diversas razones, alejaban a su primo Juan José de Lacoizqueta del cuerpo, por ejemplo.

Pedro Florentino incorporaba nuevas relaciones constituyéndose en fiador de un recién llegado, gesto que podía considerarse una inversión en un vínculo de confianza a un futuro cercano. ${ }^{110}$

En las elecciones de $1744^{111}$ fue electo alcalde de primer voto por unanimidad -sin embargo, para el oficio de alcalde de segundo voto la elección fue regulada: el teniente de gobernador Francisco Antonio de Vera Mujica (cuñado de Pedro Florentino) inclinó su voto a favor de Fernández de Teherán, candidato propuesto por Miguel Martínez del Monje. Al año siguiente Pedro Florentino fue reelecto como alcalde de primer voto sin objeciones; la razón puede encontrarse en que el capítulo estaba compuesto en su totalidad por deudos del candidato (el alguacil ma-

106 AGSF, AC, tomo X, ff.190-192, 452-453v; tomo XI, ff.208-209, 251-253; tomo XII, ff.82v.-84, 211212v, 265-267, 329 y v.; tomo XIII, ff.213-v., 250-251, 213-v.

107 En dos oportunidades representó a su tío Miguel Martínez del Monje -una en 1746 con un poder general y luego en la solicitud de arrendamiento del oficio de alférez real. AGSF, AGC, 6, Años 170748, 1733-49; legajo 19, Año 1746, ff.816/817-818.

108 ACM, Matrimonios, tomo 1717-1732, ff.11v.; tomo 1733-1764, f.31v. respectivamente.

109 En el sentido que le otorga Jeremy Boissevain, Friends of friends. Networks, Manipulators and Coalitions, Oxford, Basil Blackwell, 1974.

110 Así lo hizo con Pablo Navarro, quien pretendía el oficio de Alguacil Mayor; AGSF, AGC, 6, legajo 16, Año 1743, f.781.

111 AGSF, AC, tomo XI, ff.208-209v. 
yor Pablo Navarro; el regidor perpetuo Miguel Martínez del Monje, su tío) y presidido por su cuñado, el mentado teniente Francisco Antonio de Vera Mujica. Ellos fueron todo el cabildo: dado el carácter casi íntimo -y familiar- de la reunión, no hubo espacio para la contradicción.

En esa oportunidad, el regidor Zeballos, suspendido de su oficio y explícitamente cansado de que la familia Martínez del Monje lo quitara del medio para hacerse con la vara de primer voto, presentó ante el Cabildo un despacho del teniente general de la Gobernación que le restituía su cargo. ${ }^{112}$ Zeballos expresaba allí con claridad las maniobras que los Martínez del Monje realizaban para controlar las elecciones capitulares. Redactado por su yerno, Antonio Candioti y Mujica, el mismo cuestionaba la reelección del alcalde pero no apoyándose en los argumentos más poderosos y conocidos -como la "ley del hueco"- sino cuestionando su legitimidad a partir de que, para ser reelecto, no tuvo "[...] más voto que el suyo, el de su concuñado Don Pablo Navarro y el de su tío carnal Don Miguel Martínez del Monje, por que el Alcalde de Segundo Voto su sobrino por afinidad se fue a Chile antes de las elecciones, y el único regidor que no era de su familia ni su pariente inmediato, que fue mi suegro, le expulsaron del Cabildo en la forma referida". ${ }^{113}$ Sobre la tentativa de perpetuación del grupo en las sillas capitulares dice: "[...] que ha más de diez años sino ha veinte que la dicha vara de Alcalde de Primer Voto está vinculada a esta Casa de los Monjes, pasando de unos a otros entre hermanos, cuñados, tíos, primos, yernos, sobrinos y parientes practicando lo mismo con la de segundo voto". ${ }^{114}$ En este contexto, Zeballos solicitó al Gobernador la anulación de la reelección de Pedro Florentino de Urízar y el gobernador ordenó a su teniente, Francisco Antonio de Vera Mujica, que pusiera en posesión de su oficio a Zeballos, sin embargo no se expidió sobre la anulación de la elección. El trueque parece haber funcionado porque en 1754 y $1755,{ }^{115}$ Pedro Florentino fue electo consecutivamente y por unanimidad, como alcalde de primer voto.

\footnotetext{
112 Este caso también fue trabajado por Eduardo Saguier, Genealogía de la Tragedia. Argentina. Auge y colapso de un fragmento de estado o la violeta transición de un orden imperial-absolutista a un orden nacional-republicano (1600-1900). www.er-saguier.org., 2007.

113 Archivo General de la Nación [AGN], Sala IX, Tribunales, leg. G-6, exp.2, f.312v.

114 AGN, Sala IX, Tribunales, leg. G-6, exp.2, f.312v.

115 AGSF, AC, tomo XII, ff.211-212v., 265-267, respectivamente.
} 


\section{El hijo de María}

Un primo de Pedro Florentino, Juan José de Lacoizqueta, hijo de María Martínez del Monje y Juan de Lacoizqueta. Único hijo varón del navarro Lacoizqueta, ${ }^{116}$ a los 12 años ya era lector en la Escuela de Cristo, institución vinculada a la Congregación de la Virgen de los Milagros, en la que también su padre había sido lector entre 1709 y 1711. Aunque algunos sostienen que estudió en Europa, ${ }^{117}$ Damianovich siguiendo a Grenón- asegura que se formó en el Colegio de Monserrat (Córdoba del Tucumán).118 Entre 1711 y 1715 figura como lector en la Escuela de Cristo. El 11 de abril de 1715 se casó con Juana Ventura Márquez Montiel, hija de Antonio Márquez Montiel y de María Vargas Machuca.

También participó de la vida capitular: en $1712^{119}$ fue designado procurador general, en $1721^{120}$ fue electo alcalde de segundo voto y 1733 de nuevo procurador ${ }^{121}$ y en 1746 recaudador de arbitrios. ${ }^{122}$ En 1739, el sargento mayor había conseguido para la ciudad las provisiones que la instituían como "puerto preciso para las embarcaciones y frutos del Paraguay" que navegaran el Paraná -también una cuenta de gastos de 477 pesos y 7 reales. ${ }^{123}$ Su desempeño militar, vinculado con los cróni-

116 Archivo del Arzobispado de Santa Fe, Libro de Bautismos, 1642-1713, f.93, bautizado el 13 de mayo de 1694 .

117 Federico Guillermo Cervera, "La Casa de los Aldao", en Revista de la Junta Provincial de Estudios Históricos n. ${ }^{\circ}$, Santa Fe, 1985, p.19.

118 Allí aprobó tres años de filosofía (1708-1710) con el P. Juan de León S. J. y cursó teología en 1711, obteniendo los grados de Bachiller en Artes (1709) y Licenciado (1710). A. Damianovich, "Juan José de Lacoizqueta".

119 AGSF, AC, tomo VII, ff.122v-125.

${ }^{120}$ AGSF, AC, tomo VII, ff.191v.-193.

${ }^{121}$ AGSF, AC, tomo X, ff.135-137.

122 AGSF, AC, tomo XI, ff.330.

123 AGSF, AC, tomo X, ff.492-492v. Véase además Alejandro A.Damianovich, "El puerto preciso de Santa Fe y la dirección de los flujos del comercio interno rioplatense (Siglos XVII y XVIII)", en Revista de la Junta Provincial de Estudios Históricos n. ${ }^{\circ} \mathrm{LXIV}$, Santa Fe, 2004, Griselda Tarragó, "The long kiss of goodbye: Santa Fe and the conflict over the privilege of puerto preciso (1726-1743)", en Giuseppe de Luca y Gaetano Sabatini (eds.), Growing in the Shadow of an Empire. How Spanish Colonialism Affected Economic Development in Europe and in the World (XVIth-XVIIIth cc.), Milano, Franco Angeli Editore, 2012. 
cos problemas de defensa de la ciudad, fue considerado notable. ${ }^{124}$ En 1725 se presentó con el cargo de Sargento Mayor de Plaza, pidiendo “... certificación de los servicios prestados al Rey y a la ciudad, para cuya defensa ha hecho muchos gastos a su costa [...]”. ${ }^{125}$ Dos años más tarde, el procurador general de la ciudad propuso otorgarle poder a Juan José para comisionarlo a Buenos Aires para dialogar con el Virrey en la búsqueda de soluciones para las fronteras de la ciudad. ${ }^{126}$ En 1728 Lacoizqueta representó nuevamente a la ciudad como apoderado -junto a José de Aguirre- para tramitar la continuación del derecho de romana ante la Audiencia de Chuquisaca. ${ }^{127}$

\section{Hijos para los asuntos de Dios y de la Iglesia}

Como se adelantó, el pater familias -como lo hubiera hecho cualquier buen líder familiar en las entrañas de la monarquía hispánica- no limitó su planificación a sentar a sus hijos y sus yernos en las sillas del poder político secular. Como se ha señalado desde hace tiempo -y sobre todo como lo ha sistematizado Miriam Moriconi, investigadora que indagó esta sociedad en territorios emplazados a ambas márgenes del Atlántico- la configuración del poder político (y no se refiere solo a la jurisdiccional, sino también a las praxis de las familias que practicaban el funcionamiento del poder político) no separaba sino que articulaba los diferentes corpora. ${ }^{128}$ El caso que analizamos no es una excepción: la presencia en el cabildo secular se acompañó de una firme intención por incluir miembros de la familia en oficios eclesiásticos los cuales exceden a la función de cura de almas. La organización alrededor de la promoción del culto público patrocinando misas, procesiones, rezos etc., funcionando a la vez como un espacio de sociabilidad, un articulador social y

\footnotetext{
124 AGSF, AC, tomo IX, ff.260v.-262.

${ }^{125}$ AGSF, AC, tomo IX, ff.241-241v.

${ }^{126}$ AGSF, AC, tomo IX, ff.402-403.

${ }^{127}$ AGSF, AC, Carpeta n. ${ }^{\circ} 14 \mathrm{~A}$, ff.49v.-51.

${ }^{128}$ Miriam Moriconi, Política, piedad, jurisdicción. Cultura jurisdiccional en la Monarquía Hispánica. Siglos XVI-XVIII, Rosario, Prohistoria, 2011, particularmente la introducción.
} 
en muchas ocasiones, de un circuito de ayuda mutua entre sus miembros ${ }^{129}$ o la provisión de crédito monetario -el acceso al mismo "[...] resultaba más sencillo a quienes habían sido capaces de establecer contactos eficaces con las instituciones que lo otorgaban"-130 son algunas de las facetas más trabajadas al respecto de esta conveniencia. Todo esto alimentaba los atributos de una familia que pretendía ser percibida como prestigiosa y de consideración. La incorporación de vástagos al clero y a sus entornos se articulaba con estrategias de los grupos de elite que respondían a cuestiones de devoción, pero además, a razones materiales que contribuían a "garantizar la cohesión, la conservación y ampliación de su Patrimonio, y la reproducción de sus relaciones de poder". ${ }^{131}$ Como veremos, nuestro pater familias consideró estas y otras aristas del mundo eclesiástico. Los hijos enviados a estudiar y "elegidos" para la carrera eclesiástica fueron Juan, Pedro, Joseph e Hipólito Martínez del Monje.

\section{Oficios "espirituales": comisarios y jueces}

La religiosidad católica articulaba patrones de conducta y normativizaba en buena medida la vida social. Desde el púlpito podía censurarse o sancionarse desviaciones o los comportamientos que no se adecuaban a la moral cristiana. Además, desde el ejercicio de alguna judicatura eclesiástica, podían procesarse y castigarse una amplia gama de delitos que podían caer bajo dicha jurisdicción. ${ }^{132}$

Así, en ocasiones, a la capacidad moral se agregaba una judicial. Las dos condiciones coincidieron en la de cura párroco y vicario eclesiástico -titular de la parroquia de españoles de la iglesia matriz de Santa $\mathrm{Fe}$ - configurando un lugar

\footnotetext{
129 Susan Socolow, Los mercaderes del Buenos Aires virreinal: familia y comercio, Buenos Aires, De la flor, 1991, p.113.

130 Roberto Di Stefano, El púlpito y la plaza: clero, sociedad y política de la monarquía católica a la república rosista, Buenos Aires, Siglo XXI, 2004, p. 58.

131 R. Di Stefano, El púlpito, p.47.

132 A este respecto, véase Miriam Moriconi, "Usos de la justicia eclesiástica y de la justicia real (Santa Fe de la Vera Cruz, Río de la Plata, s. XVIII)”, Nuevo Mundo Mundos Nuevos [en línea], Debates, París, Puesto en línea el 27 octubre 2012, consultado el 11 junio 2013. http://nuevomundo.revues.org/64359.
} 
desde el cual podía ejercerse una presión considerable. ${ }^{133}$ Pero las imbricaciones entre ambos poderes eran desde luego muchas y las intersecciones permanentes -a despecho de la doctrina de las dos espadas donde todo parecía estar perfectamente distinguido y claro. El obispo podía designar jueces delegados en la ciudad; Gobernadores y Cabildos debían ser consultados y definían la ubicación donde se erigían capillas o iglesias; otorgaban autorización para establecer órdenes religiosas, para recaudar el diezmo, y además aceptaban o confirmaban los títulos de cargos eclesiásticos. Asimismo, otros cargos eclesiásticos como el de notario del Santo Oficio, tesorero del Santo Oficio de la Inquisición, síndicos procuradores de los conventos o mayordomo de cofradías podían ser ejercidos por laicos. ${ }^{134}$ De esta manera, se multiplicaban las posibilidades de beneficiarse por los privilegios del fuero inmunidad respecto del poder y jurisdicción del fuero secular, con excepción de los delitos de lesa majestad y la obligatoriedad del ejercicio de cargos concejiles o militares- con el consiguiente blindaje que esto proporcionaba a los miembros de una familia que actuaba en política.

El primero en entrar en relación con la jerarquía eclesiástica lo hizo sin ingresar al clero. El 24 de marzo de 1710, el maestro Juan Martínez del Monje fue designado comisario de la Santa Cruzada interinamente, para cubrir la ausencia del titular del cargo, titular Alonso Delgadillo y Atienza, quien viajaba hacia el Paraguay. Sin embargo, cuando Juan presentó el título de comisario sustituto ante el Cabildo, algunos capitulares se opusieron. El teniente de gobernador Ahumada hizo lugar a este rechazo, pero no arguyó incapacidad por parte de Juan, sino que no le constaban "[...] las facultades del titular para delegar su oficio [...]".135 El teniente -que tenía por fiador a Juan de Lacoizqueta, cuñado de Juan Martínez del Monjese cuidó de vetar al candidato de la familia, pero cedió a la presión de sus pares discrepando sobre la potestad que el comisario titular tuviera para delegar en un reemplazante: lo relevante, sin embargo, es silenciado. Ninguno de los actores dice que Alonso Delgadillo y Atienza fuera el padre de crianza de Isabel de Pessoa, con

\footnotetext{
133 No parece necesario recordar aquí que, desde luego, todo esto se suma a que la Iglesia católica tenía una fuerte presencia en el registro de la vida de las poblaciones (por ejemplo erigiéndose en único canal de registro y legitimación de los hitos más importantes de la vida de una persona en esta sociedad: bautismos, uniones matrimoniales, defunciones) sin omitir la organización de la caridad, la atención de los enfermos y la administración de la enseñanza de las primeras letras.

${ }^{134}$ E. Saguier, Genealogía de la Tragedia Argentina, "Las fracturas internas de la Iglesia”.

135 AGSF, AC, tomo vII, ff.25-26v.
} 
lo cual estaba comportándose respecto de Juan como un verdadero familiar, esto es, como su abuelo. ${ }^{136}$

Hacia finales del mismo año (1710) el Obispado de Buenos Aires corrigió este problema extendiendo el título de juez eclesiástico suplente a Juan Martínez del Monje “... para reemplazar, en caso de ausencia o enfermedad, al Vicario y Juez Eclesiástico de Santa Fe, Maestro Juan de Ávila y Robles”. ${ }^{137}$ Esta decisión, originada en la máxima autoridad jurisdiccional en el territorio (el obispado), no motivó ninguna objeción de parte del cabildo, que la obedeció confirmado el título.

La vinculación con el Santo Oficio se concretó siete años después: el 18 de agosto de 1717 Juan Martínez del Monje recibió el título de comisario subdelegado de la Santa Cruzada ${ }^{138}$ y ocho años más tarde, el 23 de agosto de 1725, le otorgaron el título de comisario de la Santa Cruzada. ${ }^{139}$

\section{Usos y conflictos derivados de la vara eclesiástica}

Ya se han relatado los excesos de Bracamonte durante el año $1727 \mathrm{y}$ los ataques que la familia Monje le propinó mientras que él mantuvo a Ignacio suspendido del dejercicio de su oficio de alférez real. El golpe de gracia fue intentado desde la arena eclesiástica: Juan Martínez del Monje lo excomulgó. ${ }^{140}$

A finales del año de 1731, un nuevo entredicho se suscitó entre Juan Martínez del Monje y Francisco de Vera Mujica. En esta oportunidad, el miso que había rechazado la candidatura de Juan como comisario interino, le cuestionó su accionar jurisdiccional. El comisario de la Santa Cruzada, había embargado el oficio de

\footnotetext{
136 “Dña. Isabel de Pessoa y Figueroa, la mujer de Don Francisco Martínez del Monje, quedó huérfana de madre cuando tenía once años y su padre estaba ausente de Santa Fe. Presumimos que estuvo al amparo de su tío el capitán Alonso Delgadillo y Atienza hasta que a los dieciséis años contrajo matrimonio [...]”, L. M. Calvo, "Los Martínez del Monje”, p.6o

137 AGSF, AC, tomo vII, ff.51v.-52.

138 AGSF, AC, tomo VII, ff.340-341.

${ }^{139}$ AGSF, AC, tomo IX, ff.271-272.

${ }^{140}$ AGSF, AC, tomo IX, ff.404v-408.
} 
regidor a Francisco de Vera Mujica por la radicación de una denuncia en el tribunal eclesiástico de una deuda que Vera Mujica tenía con un tercero. ${ }^{141}$

La acción molestó incluso a los miembros de su familia en el cabildo: el alcalde de segundo voto, Ignacio de Barrenechea, ${ }^{142}$ propuso que se siguieran las vías judiciales ordinarias. ${ }^{143} \mathrm{El}$ regidor propietario Miguel Martínez del Monje, hermano del comisario, acompañó al cuerpo, lo cual muestra cómo las identidades corporativas (la defensa de la jurisdicción) podía incluso molestar a los miembros de la misma familia, percibida desde afuera como monolítica y abusadora. ${ }^{144}$ Juan Martínez del Monje falleció el 9 de febrero de $1740^{145}$ y el 19 de agosto de ese mismo año es designado comisario de la Santa Cruzada Juan Antonio de Vera. ${ }^{146}$

Otro de los hijos varones de la familia, Pedro Martínez del Monje, ${ }^{147}$ fue Cura Vicario de la ciudad: fue comisionado por el cabildo eclesiástico (el obispado de Buenos Aires) y aceptado por el cabildo local como juez vicario eclesiástico en esta sede, oficio netamente jurisdiccional. Su actuación en esa clave fue, como lo ha estudiado Moriconi, muy controversial y conflictiva. ${ }^{148}$

En 1714 la rencilla entre el vicario y el cabildo se generó alrededor de la posesión de la imagen del patrono de la ciudad, San Jerónimo. El cabildo expresaba su deseo de disponer de la imagen, aduciendo que era de su propiedad. ${ }^{149} \mathrm{El}$ vicario

141 AGSF, AC, tomo X, ff.70-71.

142 Casado con Francisca Martínez del Monje y Cabrera era hija de Ignacio Martínez del Monje, hermano del Comisario Juan M. del Monje.

143 AGSF, AC, tomo X, ff.71-72v.

144 AGSF, AC, tomo X, ff.71-72v.

145 ACM, Defunciones, 1733-1764, f.13

146 AGSF, AC, tomo XI, ff.63-64v.

147 Bautizado en Santa Fe el 3 de noviembre de 1681, ACM, Bautismos, confirmaciones, matrimonios y defunciones 1642-1717, f.69. Fueron sus padrinos el Cap. don Pedro del Arco y doña Elvira de Godoy.

148 M. Moriconi, "Usos de la justicia”, estudió la causa que le siguió a un pulpero (falso alférez) por maltrato a su mujer. La autora muestra minuciosamente los pliegues de la actuación del juez al hilo de la apelación del procesado Tomás Ponce de León.

149 AGSF, AC, tomo VII, ff.226v.-227v. 
pasó del reclamo informal a la presentación de un exhorto: en su respuesta, el Cabildo le reprochó el poco respeto que mostraba por la institución y por los vecinos de la ciudad y le reprochó que el novenario a San Jerónimo por la sequía se había realizado en el convento de la Merced dado que el cura se había negado a cobrar la limosna de las misas en yerba "[...] respondiendo al mayordomo desta Ciudad con indecorosas palabras [...]". ${ }^{150}$ La devolución de la imagen a la Iglesia se hizo bajo la condición de que fuera colocada en el altar y no en la sacristía. Además le recordaron que la imagen "[...] fue fabricada a costa desta Ciudad y sus propios, y no del caudal ni rentas de los curas, ni juezes Eclesiasticos [...]". ${ }^{151}$

Estos reproches ilustran bien las zonas de fricción que podían mantener el cabildo y los miembros del clero incluso cuando la familia no tenía en el primero la mayoría absoluta. En esta ocasión se marcaban claramente ciertas dependencias que la Iglesia tenía respecto del poder temporal para poder funcionar efectivamente. El cabildo además cuestionó comportamientos del cura y hasta de su sacristán, "[...] pues los tiempos que ha estado en la Iglesia su residencia y colocacion ha sido en la sacristia con notable descuido que esta su diadema se hallo enpeñada en una taverna por el sacristan maior [...]". ${ }^{152}$ Pero en esa coyuntura, el Cabildo fue más allá y denunció los excesos cometidos por Pedro Martínez del Monje, pidiendo ayuda al Obispo y a las instancias superiores de la Justicia Real.

[...] el dho Juez Eclesiastco ronda la Ciudad de noche y atropella las Casas de los vesinos legos vasallos de su magestad maltratandolos de razones y haciendoles fuerza, prendiendolos suxetandoles los vienes de $\mathrm{q}$ ay repetidos clamores las [...] cin especial cuidado no sera usurpada la Real Jurisdiccion no las Vasallos sean arrastrados a fuero, que no deven en materias temporales, y no anejas, ni dependientes a la Juridiccion Ecleciastica, sobre que le exorten, y requieran y sobre todo se informe al Ex.mo [...] Señor obispo deste obispado, y sede quenta a los demas tribunales superiores Reales . [...].153

\footnotetext{
150 AGSF, AC, tomo VII, ff.226v.-227v.

151 AGSF, AC, tomo VII, ff.226v.-227v.

152 AGSF, AC, tomo VII, ff.226v.-227v.

153 AGSF, AC, tomo vII, ff.226v.-227v.
} 
La denuncia, firmada por el cabildo, es en realidad lo que una parte de la vecindad de Santa Fe percibe: la utilización que la familia Martínez del Monje hacía de la autoridad religiosa para perseguir y denostar a los adversarios de la coalición con la que tenían relaciones dentro de la institución capitular, donde se podía conseguir preeminencia o hegemonía pero no siempre unanimidad.

En las elecciones capitulares de 1715, el alférez real Ignacio Martínez del Monje había objetado a los vecinos propuestos para alcaldes ordinarios -uno por ser capitular propietario y al otro por tener una causa pendiente en la Real Hacienda. ${ }^{154}$ De su lado, el regidor propietario Francisco de Vera Mujica había objetado a los candidatos propuestos por el alférez real arguyendo consanguinidad. Vera $\mathrm{Mu}-$ jica consiguió la mayoría de los votos, la aprobación del teniente de gobernador y la confirmación del gobernador. ${ }^{155}$ La familia Martínez del Monje debió haber contado con el apoyo al menos del teniente, porque -según hemos documentado- no se hizo esperar un ataque artero con la vara eclesiástica.

El 24 de febrero de 1715, Andrés López Pintado (alcalde de primer voto del partido de Vera Mujica) convocó un acuerdo extraordinario para informar que el teniente de gobernador Martín de Barúa había sido excomulgado. ${ }^{156} \mathrm{El}$ alférez Ignacio Martínez del Monje, hermano del vicario que había realizado la excomunión, faltó al acuerdo con la excusa de que era día feriado. El acta registra una consulta a las leyes de Castilla y la Recopilación de Indias que transcribe ${ }^{157}$ y una fe pública de lo sucedido con la excomunión del teniente de gobernador. El escribano afirmó que el día anterior, como a las cuatro de la tarde, tres eclesiásticos (el Doctor Don Joseph del Monje [hermano del vicario], y los licenciados Joseph de Brito y Gerónimo

\footnotetext{
154 Ver ut supra, AGSF, AC, tomo VII, ff.246-250v.

155 AGSF, AC, tomo VII, ff.254-254v.

156 “[...] el motivo de esta junta a referido era el hallarse desde ayer fijado pr. Publico excomulgado el Sr. Mre de Campo Dn. Mrn de Barua The.te Gen.l de Governador Justicia may.r y cap.n a Guerra a las puertas de la Ig.a Matris; y siendo materia tan grave pr recaer en el Principal Ministro [...]", AGSF, AC, tomo VII, f.258.

${ }^{157}$ Leyes de Indias, libro I, título VII, ley XVIII dice: "Rogamos y encargamos a los Arçobispos y Obispos de todas y qualesquir Ilgesias Metropolitanas y Catedrales [...] y á sus Vicarios, Oficiales, Provisores, y demas Iuezes Eclasiasticos de ella, que quando sucediere algun caso en que haya de adsolver á alguno de nuestros Oidores, Alcaldes, Corregidores, Governadores, ó otros nuestros Iuzes y iusticias, ó sus Ministros y Oficiales [...] les concedan la absolucion llanamente, como se practica en estos nuestros Reynos de Castilla, y no los obligue á ir personalmente á recibirla de sus propias personas, y a sus casas Episcopales [...]”.
} 
Barreto) entraron a la casa del Justicia mayor y le entregaron un exhorto según el cual, de no liberar al alguacil Lucas de Torres, a quien el teniente tenía preso por haberle incoado una causa en el tribunal eclesiástico, sería multado con 500 pesos y excomulgado. No habiéndolo cumplido, a la media hora ya lo habían declarado "[...] incursso en la Ta[bli]lla de la sena fixandole por publico excomulgado [...]"..158

El escrito muestra cómo ambos justicias y ambas justicias disputaban sobre una persona pero, en realidad, muestran cómo los ardides judiciales se utilizaban para dañar al otro personal y políticamente. Pedro Martínez del Monje, juez vicario del obispado en la ciudad, creía tener la facultad de exigir una excarcelación judicialmente decidida por la máxima autoridad a nivel local -el teniente de gobernador era el justicia mayor- pero además ya había realizado la excomunión con la cual le amenazaba, sin admitir ningún descargo del teniente. ${ }^{159}$

El cabildo -sin la presencia de Ignacio Martínez del Monje- inició acciones legales ante la Real Audiencia de la Plata sobre competencia de jurisdicción y solicitó al Vicario que enviara a la misma Audiencia los autos obrados contra el teniente de gobernador Barúa. ${ }^{160} \mathrm{El} 20$ de marzo de 1715, el alcalde de primer voto informó que el teniente había sido excomulgado y que su nombre figuraba en la tablilla a las puertas de la Iglesia matriz y de los demás conventos. ${ }^{161} \mathrm{El}$ escribano, en calidad de testigo, dijo que la confirmación de la pena se debió a que Barúa no cumplió con las dos citaciones que le formuló el Juez Eclesiástico para obedecer un despacho real. Pero el cuerpo, como si no hubiera comprendido la inobservancia de forma señalada por el escribano, resolvió que: “[...] atendiendo a ser en ofensa y daño de la Real Jurisdiccion [...] se acordo sele despache exorto para que absuelva dentro de una hora al dicho Sr. Justicia mayor d por ultimo y peremtorio termino [...]”.162

Los dos capitulares comisionados al efecto fueron rechazados y amenazados de excomunión por el juez vicario eclesiástico, Pedro del Monje. El cabildo insistió al día siguiente y el vicario accedió a levantar la excomunión del teniente bajo protesta. Barúa, repuesto en su función, brindó a los capitulares su punto de vista so-

\footnotetext{
158 AGSF, AC, tomo VII, ff.257-258v.

159 AGSF, AC, tomo VII, ff.257-258v.

160 AGSF, AC, tomo vII, f.178v.

161 AGSF, AC, tomo VII, ff.180-181.

162 AGSF, AC, tomo VII, ff.180-181.
} 
bre el episodio y realizó una propuesta: interpretó su excomunión como un acto dirigido solo a usurpar "[...] la Real Jurisdiccion [...]" y pidió la asistencia de cuatro capitulares para exhortar ante los Reales ministros el cumplimento de las leyes regias. ${ }^{163}$ Los autos fueron enviados al gobernador y a la Audiencia de La Plata, mientras que al notario eclesiástico se le hizo llegar un testimonio con un resumen de lo actuado. El primer día de agosto del mismo año, una carta del Obispo de Buenos Aires anunciaba al cabildo que el oficio de vicario y juez eclesiástico había sido otorgado al maestro José Antonio Meléndez. ${ }^{164}$ En esta ocasión, tampoco se hizo presente el alférez real, quien se excusó alegando estar enfermo. ${ }^{165}$

Como puede apreciarse, en este enfrentamiento el planteo de usurpación de la jurisdicción Real por la eclesiástica debe insertarse en un conflicto que le da sentido, cual es el de la competencia por la supremacía en el cabildo local por dos coaliciones que no siempre conseguían imponerse sin pasar por este tipo de ritualización de la disputa política. Durante este año (1715) los Martínez del Monje quedaron fuera de los oficios jurisdiccionales ordinarios y, como no pudieron prevalecer ni siquiera a través de la figura del alférez -Ignacio faltó a todos los acuerdos mientras duró el conflicto-, echaron mano de otro dispositivo para perturbar a la coalición de los Vera Mujica haciendo sentir a Martín de Barúa lo fuerte que podían jugar incluso contra un teniente de gobernador. Pedro, aunque desplazado como juez vicario eclesiástico en agosto de 1715, no perdió sus fueros ni sus atributos y -como se dijo- el 9 de marzo de 1728 fue nombrado comisario de la Santa Inquisición en reemplazo de Pedro Gonzáles Bautista, jubilado por su "crecida edad y achaques". 166

Otro ejemplo sobre este mismo tópico se expresó durante las elecciones de 1745, cuando Pedro Florentino de Urízar fue reelecto alcalde de primer voto gracias a que los miembros de la familia Martínez del Monje neutralizaron la segura oposición que esto despertaría en el regidor Juan de Zevallos. El relato del episodio proviene de la pluma de Antonio Candioti y Mujica, representante y yerno de Juan de

\footnotetext{
163 AGSF, AC, tomo VII, ff.181-183.

164 AGSF, AC, tomo VII, ff.191-192.

165 AGSF, AC, tomo VII, ff.191-192.

166 AGSF, AC, Carpeta 14A, ff.78v-8ov.
} 
Zevallos. ${ }^{167}$ Se dirigió al gobernador denunciando que los Martínez del Monje habían diseñado una maniobra para despojar a Zeballos de su oficio y, de esa manera, alejarlo del cuerpo capitular.

[...] Considerando que el expresado Dn Juan de Zevallos no Concurriría con su Voto a dicha Reelesion y por lo Consguiente como tenian dispuesto. Se Valieron del indecorosso medio de induzir secretamente a el Maestro Don Pedro Martinez del Monje hermano del Rexidor Don Miguel Martines del Monje tio del enunciado Don Pedro Florentino de Urizar y comisario del Santo oficio de la Inquisision de aquella Ciudad a que embarazase la persona y vienes del dho Rexidor Don Juan de Zevalos suponiendole Reo contra Su tribunal por dezir havia defendido aora tiempos los Reales Intereses del Tribunal de la Santa Cruzada y que aconsejava al Dotor Don Juan Antonio de Vera Su comisario en la ciudad de Santa fee lo que devia executar y practicar en Orden a la Cobranza de Cantidad de Pesos que estaban deviendo algunos parientes muy Inmediatos de los mismos Cavildantes [...]. ${ }^{168}$

Efectivamente, el 24 de diciembre - cuando generalmente se realizaba la calificación de votos y se proponían los candidatos para ocupar los oficios del año siguiente- el comisario Pedro del Monje envió al Cabildo un exhorto por medio del alguacil mayor participando que tenía puesta caución y suspendido en su oficio a Juan de Zevallos. ${ }^{169}$ Según Candioti, Pedro del Monje había hecho esto claramente para que no lo admitiesen en las votaciones. ${ }^{170}$

El representante de Zevallos pidió al Gobernador que sancionara a los miembros del cabildo, sobre todo al teniente y al alcalde, invocando connivencia con el avance de la jurisdicción eclesiástica sobre la Real y por ocultar el ardid del exhorto cuando se envió la copia de las elecciones para que el gobernador la apro-

\footnotetext{
167 Antonio Candioti y Mujica se había casado en Santa Fe con Andrea de Zeballos el 6 de junio de 1742. Ver Federico Cervera y Manuel M. Cervera, "Don Francisco Antonio Candioti - Primer Gobernador Independiente de Santa Fe, 1743-1815", en Revista de la Junta Provincial de Estudios Históricos $\mathrm{n} .^{\circ}$ VII, Santa Fe, 1942, pp.11-16.

168 AGN, Sala IX, Tribunales, leg. G-6, exp.2, f.310.

169 AGSF, AC, tomo XI, ff.248-250.

${ }^{170}$ AGN, Sala IX, Tribunales, leg. G-6, exp.2, f.311.
} 
bara. ${ }^{171}$ Candioti pidió además que se sancionara al comisario de la Santa Inquisición Pedro del Monje, porque el caso por el cual se lo acusaba llevaba bastante tiempo y éste hacía seis meses que estaba en la ciudad. Su presunción era que si el comisario hubiera querido podría haber accionado antes, pero que voluntaria y estratégicamente espero al momento de las elecciones para hacerlo. ${ }^{172}$

El promotor fiscal del caso, Martín Gutiérrez de Valladares, transcribió un fragmento de la carta -atribuida a un sujeto independiente- que el suegro de Candioti había recibido días antes de la notificación del exhorto del juez eclesiástico, donde se sugieren los protagonistas y los artilugios de la maniobra denunciada:

[...] Prevengo a Vm. que Urizar pretende ser reelecto, y para conseguirlo aunque en lo aparente an echo buen resevimiento a Don Juan de Zeballos (esto es al uso de su oficio con el despacho que llevo de Us.) pero han asegurado que por voto de cuerda han estimulado a Don Pedro del Monje para que renuebe o refresque la causa que le tenia echa y no sea admitido a votar el dia del año nuevo $[\ldots] .173$

Un tercer hijo de la familia, Joseph Martínez del Monje, fue sacerdote, cura de la parroquia de españoles, vicario juez eclesiástico y -al igual que sus otros dos hermanos- comisario del Santo Oficio. ${ }^{174}$ El 23 de febrero de 1725 fue designado como vicario y juez eclesiástico en lugar del Maestro Pedro Gonzáles Bautista, decisión que tomó el Obispo debido a la querella que el Cabildo de Santa Fe tenía en

171 "[...] Obedesieren puntualisimamente abandonando al cumplimiento de su Obligacion en la defenza de la Jurizdizion Real que les pertenesia y tanto encarga su magestad (que Dios Guarde) Sin replica alguna dando a dicho comisario de Inquisision mas obedezimiento que a el Despacho presentado de este Govierno como si fueze Juez Superior a todos por lo que deven Ser Penados pues no Debian Obedeser al tal exsorto. [...] Tersero por que en las eleciones que habran remitido a Su señoria para su confirmacion no le abran remitido el exsorto de dicho comisario de Inquisicion ni se daran por entendido de el [...]”. AGN, Sala IX, Tribunales, leg. G-6, exp.2, f.312.

172 AGN, Sala IX, Tribunales, leg. G-6, exp.2, ff.324-324v.

173 AGN, Sala IX, Tribunales, leg. G-6, exp.2, f.326.

174 Archivo Histórico Arzobispado Santa Fe de la Vera Cruz, Querellas, tomo II, Buenos Aires, 19 de febrero, 1734; traslado a Santa Fe firmado 23 de febrero de 1734, ff.66-68; Miriam Moriconi, "Diversidad institucional y conflictos jurisdiccionales. El clero santafesino en el siglo XVIII", en Gabriela Alejandra Caretta y Isabel Zacca (comps.), Derroteros en la construcción de religiosidades sujetos, instituciones y poder en Sudamérica, siglos XVII al XXI, Salta, Centro Promocional de Investigaciones en Historia y Antropología-CEPIHA, 2012. 
contra de Gonzáles Bautista. ${ }^{175}$ Cinco años más tarde, Joseph otorgó un poder a Francisco Piquer en Madrid "[...] para La Pretension de silla Prevenda o dignidad y acernos de ellas canonicatto o veneficio en el Gno de la Santa Iglesia Cathedral del Puerto de Bs Aires o ciudad de Cordoba Prov.a del Tucuman [...]”.176

En su testamento se menciona que había otorgado $\$ 500$ en Plata acuñada para esta silla -la compra de estas sillas era el correlato eclesiástico al de las regidurías seculares, también estaban en venta aunque los requisitos para su adquisición eran algo más onerosos, incluían por ejemplo un doctorado en cánones [...]- y que como hasta ese momento no la había podido obtener, su voluntad era que en el caso de morir, si la silla fuera otorgada, fuera ocupada en primer lugar por su hermano Pedro y si tuviera algún impedimento en su hermano Juan -lo cual expresa la jerarquía que él mismo se había compuesto. ${ }^{177}$

Por último, Hipólito Martínez del Monje, otro de los hijos de Isabel y Francisco Martínez del Monje, se ordenó como religioso jesuita en Córdoba alrededor de 1698. Al momento de ordenarse, la familia destinó en su cesión de bienes $\$$ 2000 para la fundación de una beca en el Colegio de Nuestra Señora de Monserrat, agregando una cláusula "[...] prefiriendo como prefiero en primer lugar, mi tio Ignacio Pesoa, hijo de mi abuelo el general Nicolás de Pessoa y Figueroa". ${ }^{178}$ Cuando sus hermanos Juan y Pedro hicieron su preparación religiosa en Córdoba y renunciaron sus bienes en favor de su madre, ya que su padre había fallecido.

Otros miembros de la familia aunque no siguieron la carrera eclesiástica, tuvieron lazos fuertes con instituciones religiosas: Pedro Florentino de Urízar en 1732 fue admitido como familiar del Santo Oficio ${ }^{179}$ y en 1737 el comisario de la Santa Cruzada Juan Martínez del Monje comunicó los nombramientos de tesorero y al-

\footnotetext{
175 AGSF, AC, tomo IX, ff.234-235v.

176 Poder especial para pretensión de silla canonical de Dn Joseph Martínez del Monje en Madrid a Dn Fco Piquer, otorgado en Santa Fe el 1 de abril de 1730. DEEC, SF, EP, tomo XII, ff.25v.-26v.

177 Testamentaria de Joseph Martínez del Monje, otorgada en Santa Fe el 23 de mayo de 1733. DEEC, SF, EP, tomo XII, ff.477-478v.

178 Citado por Pedro S. J. Grenon, "Jesuitas santafesinos" en Revista de la Junta Provincial de Estudios Históricos de Santa Fe n. ${ }^{\circ}$ 2, Santa Fe, 1936, pp.63-64.
}

179 AGSF, AC, tomo X, ff.89v.-90 v. 
guacil mayor para ese juzgado a Pedro de Urízar y a Pablo Navarro. ${ }^{180}$ Juan de Lacoizqueta fue mayordomo de la cofradía del Santísimo Sacramento, una de las más importantes de la ciudad. ${ }^{181}$

\section{Prestigio, relaciones y privilegios}

Si bien algunos oficios capitulares podían adquirirse a través de una subasta pública, es cierto que la misma no era abierta ni se podía pujar en ella libremente entre muchos candidatos de los cuales salía favorecido el mejor postor. ${ }^{182}$ La obtención de la información circulaba entre unos pocos y, en este sentido, era un bien preciado en sí misma.

De los cargos con sede en cabildo, se remataban los que correspondían a funcionarios especiales, el de escribano y luego las regidurías. Es posible que en Santa Fe se hubiera venalizado tempranamente el de fiel ejecutor. ${ }^{183}$ De ese modo mermaron los miembros puramente electivos, quedando reducido a los alcaldes ordinarios. En muchos cabildos, cuando los oficios subastados no alcanzaban para cubrir los asientos, las regidurías perpetuas convivieron con las electivas. La particularidad que se presenta en el caso santafesino con respecto a los oficios jurisdiccionales y su exclusión de los oficios venales tiene estrecha relación entonces con el privilegio que obtuvo la ciudad en 1715 para poder elegir en los cargos de alcalde ordinario de primer y segundo voto a regidores propietarios: como se comprende, la venalidad de la regiduría adquirida contaminaba al oficio jurisdiccional.

180 AGSF, AC, tomo X, ff.382-384v.

${ }^{181}$ Carta de poder de Juan de Lacoizqueta como mayordomo de la cofradía del santísimo sacramento a Joseph de Rivarola hermano de la cofradía y Tte. de gobernador de San Juan de Vera de las siete Corrientes. DEEC, SF, EP, tomo VIII, ff.267v.-269.

182 Zacarías Moutoukias, “Gobierno y sociedad en el Tucumán y el Río de la Plata, 1550-180o”, en Enrique Tandeter (dir.), Nueva Historia Argentina. La Sociedad Colonial, Buenos Aires, Sudamericana, 2000, pp.355-411.

183 Para ver las fechas más tempranas de venalización de los oficios en Santa Fe y Buenos Aires, Darío Darío G. Barriera, "Ordenamiento jurídico y política en los bordes de la Monarquía Católica. Reflexiones en torno al oficio de alguacil mayor (Santa Fe, Gobernación del Río de la Plata, 15731630)", en Revista de Historia del Derecho n. ${ }^{\circ} 39$, Buenos Aires, Instituto de Investigaciones de Historia del Derecho, 2010 en línea. 
Este privilegio -que, como además se ha explicado, los propios beneficiarios hicieron valer como si fuera la costumbre de la ciudad-se convirtió en otro de los caminos hacia la venalización indirecta de los oficios judiciales. El primero fue la compra del oficio de alférez real seguida de la implementación de su preeminencia a la hora del reemplazo de los alcaldes. Entonces, si la adquisición de regidurías formaba parte de un comportamiento articulado - es decir, si las regidurías eran controladas por un grupo que realmente funcionaba coaligadamente- las posibilidades de hegemonizar la toma de decisiones en el cabildo eran muchas, deteriorando en consecuencia uno de los atributos más valorados de los ámbitos capitulares (su autonomía y su pluralismo) y lesionando el atributo más nítido de la indisponibilidad de la majestad regia -figurada en los oficios jurisdiccionales. ${ }^{184}$

La compra de regidurías y alferecías fue otra de las arenas donde quienes intentaban conducir coaliciones políticas locales dieron disputas fuertes. Vecinos que hubieran alcanzado una cierta notabilidad por descollar cultural o socialmente, vieron estrechar sus posibilidades ante la falta de dinero y conexiones -dos de las tres cosas necesarias para adquirir un oficio. La propuesta de candidatos y la elección de los oficios de alcalde la hacían los regidores propietarios, con lo cual no tenían ya ninguna dificultad en realizar un filtro entre quiénes eran los "elegibles". Luego, el mencionado privilegio del cabildo santafesino a que los propios regidores propietarios pudieran ser electos como alcaldes de primer o segundo voto allanó el camino. En el periodo que estudiamos, este conducto se verifica en 19 ocasiones, y los nombres de quienes lo transitaron nos resultan a estas horas familiares: Pedro Rodríguez (en 1702), Francisco de Vera Mujica (en 1709 y 1732), Melchor de Gaete (en 1714), Tomás de Noseda (en 1718), Pedro de Zavala (en 1725 y 1738), Juan de Zevallos (en 1725, 1728 y 1733), Miguel Martínez del Monje (en 1730, 1736, 1737 y 1740), Andrés López Pintado (en 1731 y 1732), Pedro de Arismendi (en 1736) y Manuel Maciel (en 1741). ${ }^{185}$

De la lista se deduce que no fue el principal método de la casa de los Monje: de allí, entonces, se agiganta su aptitud para combinar este con los muchos otros artilugios descriptos a lo largo del artículo.

\footnotetext{
${ }^{184}$ Sobre venta de oficios y el resguardo de la jurisdicción ver Francisco Tomás y Valiente, La venta de oficios; con I. Gómez González, La justicia en almoneda.

185 Listado confeccionado con base en AGSF, AC, tomos VI, VII, VIII, IX, X y XI.
} 


\section{Conclusiones}

Antes de terminar, nos gustaría resumir con algunas citas la percepción que de este clan familiar tenían quienes se veían perjudicados por ella.

En $1735^{186}$ la ausencia del alcalde segundo José Márquez Montiel motivó que Juan de Zevallos reclamara el depósito de la vara en su persona, por su calidad de segundo regidor más antiguo. Lo hizo invocando autos del Gobernador Zavala, que establecían precisamente que ante la ausencia de alcaldes ordinarios las varas debían ser asumidas por el alférez real o por el regidor más antiguo, y que si este último estaba a cargo del turno de fiel ejecutor, el reemplazo lo hiciera el regidor que le sigue en antigüedad. Francisco de Vera Mujica era por entonces el regidor decano, pero a cargo del turno de fiel ejecutor. Zevallos seguía en el orden jerárquico, pero como en otras ocasiones, al producirse una vacante se encontraba suspendido, lo cual en otro momento benefició en varias ocasiones al difunto Ignacio Martínez del Monje. Lo que se escondía detrás de esto era otro ardid: desde la muerte de Ignacio, el alcalde segundo era quien tenía en depósito el estandarte real y, con él, sus prerrogativas.

Estas complejas articulaciones de precedencias para los reemplazos constituían parte de los saberes que aceitadamente manejaban los Monje. Nada ocurría como fruto de la casualidad. Eso es lo que pensaba Antonio Candioti, el yerno de Juan de Zeballos, quien escribió al gobernador: "[...] no ay Vesino que se atreva a haser postura ni en propiedad ni en arrendamiento a qualquiera de todas las demas varas de aquel cavildo que ha muchos años estan vacas y lo estaran siempre sino se remedian estos Desordenes en que S. M. pierde tantos Intereses [...]”. 187

El mismo hombre señaló más adelante que toda la construcción de vínculos de los Monje había sido fraguada con el "[...] ánimo de no tener otro en el Cabildo que pueda embarazarles sus operaciones". ${ }^{188}$ El vocero de Juan de Zevallos también los retrató de esta manera: "[...] en un año son partes y en otro año son jueces en

\footnotetext{
186 AGSF, AC, tomo X, f.237 v.

187 AGN, Sala IX, Tribunales, leg. G-6, exp.2, f.312.

188 Antonio Candioti y Mujica, en el Expediente sobre unas haciendas de mulas y caballos que se enviaron desde Santa Fe hacia Colonia de Sacramento, año 1740. AGN, Sala IX, Tribunales, leg. G-6, exp.2, f.312v.
} 
los mismos autos y causas [...] por lo que todas las demás familias de aquel vecindario viven ajadas y ultrajadas expuestas a dejar sus casas y conveniencias mudándose a otra ciudad por el conocido agravio que en éstas se les hace.”189

La mirada de los perjudicados es parcial y cargada de intereses, pero no está completamente desprovista de verdades. Aunque en este artículo hemos hecho énfasis en el cómo y no en el para qué, e incluso si esos discursos opositores forman parte de una esgrima en la disputa por espacios de poder político, resumen bien las razones por las cuales la casa de los Monje desarrollaba sus estrategias.

Desde la llegada del fundador de la familia en 1666 y sobre todo con la constitución de los vínculos surgidos a través de los matrimonios de sus hijos e hijas y de la ubicación de algunos de sus hijos y yernos en oficios jurisdiccionales seculares y eclesiásticos, los hombres de la familia Martínez del Monje iniciaron un proceso en el que fueron invadiendo capilarmente los espacios políticos de la ciudad, tanto temporales como espirituales. Disputaron y sostuvieron esas posiciones fortaleciendo vínculos que ayudaron a presionar a los grupos opositores, pero también negociando momentos de acuerdo o esgrimiendo paciencia durante los años que no pudieron adquirir una presencia hegemónica. La familia recurrió a la solvencia económica para financiar estudios, comprar oficios y hasta hacer fuertes donativos.

La reconstrucción de esta biografía colectiva, desde su aspecto político, contribuye a demostrar cómo los agentes interpretan y reinterpretan diferentes niveles de producción de derecho (real, provincial y local) según las diferentes coyunturas y conveniencias, trabajando sobre la elaboración de reglas de juego o desplegando estratégicas habilidades de presión que les permitieran sortear dificultades cuando las herramientas jurídicas no se ajustaban perfectamente a sus intereses.

En el transcurso de los primeros cincuenta años del siglo XVIII, momento en que los Monje se consolidaron en el poder político local, los oficios de alcalde de $1^{\mathrm{o}}$ y $2^{\circ}$ voto fueron ocupados en 26 oportunidades por alguno de ellos en forma electa. Otras 11 veces fueron desempeñados de forma interina por Miguel Martínez del Monje y otras 3 fueron interinatos de Ignacio Martínez del Monje. En suma, entre 1700 y 1750 los cargos de mayor importancia en el cabildo, las alcaldías de $1^{\circ}$ y $2^{\circ}$ voto, fueron ocupados en 40 ocasiones por algún miembro de esta familia. Además hay que agregar que Juan de Lacoizqueta fue teniente de gobernador durante dos

189 Antonio Candioti y Mujica, 2 de febrero de 1745, en AGN, Sala IX, Tribunales, leg. G-6, exp.2, f.312v. 
años, Ignacio Martínez del Monje ejerció como alférez real durante 17 años, y Juan de Rezola como tesorero durante otros 3. A partir de 1725 hasta 1749 (año en que testó) Miguel Martínez del Monje tuvo una regiduría perpetua y, para bien y para mal, Francisco de Bracamonte fue tesorero real por 21 años seguidos.

Si la familia Martínez del Monje logró acceder a los resortes más importantes del poder político local y retenerlos por cincuenta años no se debió solo a una inversión económica en la adquisición de oficios venales sino a la combinación de varias destrezas. Por un lado, a la construcción de una red de relaciones sólida -no rígida, sino sólida, esto es, permisiva y eficaz para hacer circular favores y deudasy con considerable permanecía en el tiempo. Por el otro, cuando las relaciones no fueron suficientes para lograr un lugar expectable en la institución capitular, supieron esperar y cultivaron el precioso arte de la paciencia y trataron de horadar el prestigio, la buena fama y hasta la tranquilidad de sus oponentes. Para esta labor fue determinante la ocupación de oficios eclesiásticos, desde los cuales diversos miembros de la familia fungieron al servicio del clan cuando otros dispositivos no permitían el logro de los objetivos perseguidos -se llegó al extremo de amenazar con una excomunión a un teniente de gobernador. Por último, para explicar su preeminencia, a la combinación de sus virtudes debe agregarse el relativo fracaso de sus contrincantes a la hora de consolidar vínculos que le posibilitaran sostenerse en el espacio político bajo la presión de las maniobras de los Monje.

Sin embargo, la ocupación de diversos lugares políticamente relevantes no hubiera alcanzado para minimizar los obstáculos que sus opositores interpusieron en sus objetivos si no hubiera mediado ese tipo de saber tan particular que consiste en la habilidad para disponer de piezas "legales" en toda ocasión. Hemos visto cómo desempolvaron cédulas, ordenanzas o títulos de leyes desde siempre conocidas pero sólo coyunturalmente útiles.

Las estrategias y habilidades utilizadas por este clan a la hora de lograr sus objetivos fueron diversas. Desde los muchos saberes jurídicos, políticos y judiciales hasta los abusos y las persecuciones informales, la reconstrucción permite retratar, en un escenario local, las diferentes dimensiones del poder político que podían ponerse en juego en una arena local alejada de los centros neurálgicos del poder político, que no por esta condición estaba desierta de hábiles prácticos en refinados procedimientos que pertenecían a una cultura política común a las monarquías confesionales europeas. 


\section{Bibliografía}

Fuentes Primarias:

Archivo de la Catedral Metropolitana de Santa Fe (ACM), Matrimonios (M).

Archivo General de la Nación [AGN], Sala IX, Tribunales.

Archivo General de la Provincia de Santa Fe (AGSF) Actas Capitulares (AC).

Archivo Histórico Arzobispado Santa Fe de la Vera Cruz, Querellas.

Departamento de Estudios Etnográficos y Coloniales de Santa Fe (DEEC, SF).

\section{Fuentes secundarias:}

Aldao Ocampo, Federico, Genealogía - Hombres de Mayo, Buenos Aires, RIACG, 13, 1961, pp.13-383.

Álvarez-Ossorio Alvariño, Antonio, "La venta de magistraturas en el reino de Nápoles durante los reinados de Carlos II y Felipe v", en Chronica Nova, n. ${ }^{\circ} 33$, Granada, Universidad de Granada, 2007, pp.57-94.

Andújar Castillo, Francisco, Necesidad y venalidad. España e Indias, 1704-1711. Madrid, Centro de Estudios Políticos y Constitucionales, 2008.

Balandier, Georges, El poder en escenas. De la representación del poder al poder de la representación, Barcelona, Paidós, 1994.

Barriera, Darío G., "Un rostro local de la Monarquía Hispánica: justicia y equipamiento político del territorio al sureste de la Real Audiencia de Charcas, siglos XVI y XVII", in Colonial Latin American Historical Review vol.15, n. ${ }^{\circ}$, Albuquerque, New Mexico University, 2006, pp.377-418.

Barriera, Darío G., "Resistir al Teniente con la letra del Rey: la conflictiva relación del Cabildo de Santa Fe con la Gobernación del Río de la Plata, años 1620”, en Gabriela Dalla Corte, Pilar García Jordán, et al (coords.), X Encuentro Debate América Latina Ayer y Hoy: homogeneidad, diferencia y exclusión en América, Barcelona, Universidad de Barcelona, 2006, pp.65-72.

Barriera, Darío G., "Ordenamiento jurídico y política en los bordes de la Monarquía Católica. Reflexiones en torno al oficio de alguacil mayor (Santa Fe, Gobernación del Río 
de la Plata, 1573-1630)”, en Revista de Historia del Derecho n. ${ }^{\circ} 39$, Buenos Aires, Instituto de Investigaciones de Historia del Derecho, 2010 en línea.

Barriera, Darío G., "La dimensión política de un oficio de vara en los bordes de la Monarquía hispánica: reflexiones sobre el alguacilazgo mayor en Santa Fe la Vieja (Gobernación del Río de la Plata, 1573-1660)", en Chronica Nova n. ${ }^{\circ} 37$, Granada, Universidad de Granada, 2011, pp.69-98.

Barriera, Darío G., Abrir puertas a la tierra. Microanálisis de la construcción de un espacio político (Santa Fe, 1573-1640), Santa Fe, Museo Histórico Provincial, 2013.

Barriera, Darío G., "Entre el retrato jurídico y la experiencia en el territorio. Una reflexión sobre la función distancia a partir de las normas de los Habsburgo sobre las sociabilidades locales de los oidores americanos", en Caravelle n. ${ }^{\circ} 101$, Toulouse, 2013, pp.133-154.

Birocco, Carlos María, "La pesquisa de Mutiloa en Buenos Aires. Conformación de facciones y lucha por el poder en el cabildo porteño (1700-1715)", en Ma. Paula Polimene (coord..), Autoridades y prácticas judiciales en el Antiguo Régimen. Problemas jurisdiccionales en el Río de la Plata, Córdoba, Tucumán, Cuyo y Chile, Rosario, Prohistoria, 2011, pp.33-56.

Boissevain, Jeremy, Friends of friends. Networks, Manipulators and Coalitions, Oxford, Basil Blackwell, 1974.

Calvo, Luis María, "Lacoizqueta”, en Revista Genealogía n. ํ18, Buenos Aires, 1979.

Calvo, Luís María, "Martínez del Monje", en Boletín del Instituto Argentino de Ciencia Genealógicas vol.XII, n. ${ }^{\circ} 158$, Buenos Aires, 1988.

Cervera, Felipe Justo, "Nepotismo y Economía en Santa Fe Siglos XVII a XX”, en Revista de la Junta Provincial de Estudios Históricos de Santa Fe n. ${ }^{\circ} \mathrm{LXIV}$, Santa Fe, 2004.

Cervera, Federico y Cervera, Manuel M, "Don Francisco Antonio Candioti - Primer Gobernador Independiente de Santa Fe, 1743-1815”, en Revista de la Junta Provincial de Estudios Históricos n. ${ }^{\circ} \mathrm{VII}$, Santa Fe, 1942, pp.11-16.

Cervera, Manuel María, Historia de la ciudad y provincia de Santa Fe. Contribución a la Historia de la República Argentina 1573-1853, $2^{\text {a }}$ edición, tomo II, Santa Fe de la Vera Cruz, UNL, 1980 [1907].

Cervera, Manuel María, Historia de la ciudad y provincia de Santa Fe. Contribución a la Historia de la República Argentina 1573-1853, $2^{\mathrm{a}}$ edición, tomo III, Santa Fe de la Vera Cruz, UNL, 1982 [1907].

Cervera, Federico Guillermo, "La Casa de los Aldao", en Revista de la Junta Provincial de Estudios Históricos n. ${ }^{\circ}$ L, Santa Fe, 1985. 
Crespo Naón, Juan Carlos, La sociedad santafesina: génesis y evolución, Buenos Aires, SNT, 1983.

Damianovich, Alejandro A., “Juan José de Lacoizqueta. Gestor del privilegio santafesino del Puerto Preciso”, en Revista América n. 10, Santa Fe, 1991.

Damianovich, Alejandro A., "El puerto preciso de Santa Fe y la dirección de los flujos del comercio interno rioplatense (Siglos XVII y XVIII)", en Revista de la Junta Provincial de Estudios Históricos n. ${ }^{\circ} \mathrm{LXIV}$, Santa Fe, 2004.

Di Stefano, Roberto, El púlpito y la plaza: clero, sociedad y política de la monarquía católica a la república rosista, Buenos Aires, Siglo XXI, 2004.

Fernández de Burzaco y Barrios, Hugo, "Fundadores de linajes en el Plata”, en Genealogía n. ${ }^{0} 11$, Buenos Aires, 1955 .

Forconi, M. Celeste, "Interesse em conflito entre a prática e a legalidade: o exercício do poder político em Santa Fé (século XVIII)”, em Métis: história \& cultura, Universidade de Caxias do Sul/Centro de Ciências Humanas/Área de História, Caxias do Sul- Brasil vol.XIII, n. ${ }^{\circ}{ }_{25}$, 2014, pp.59-83.

Fucé, Pablo, El poder de lo efímero. Historia del ceremonial español en Montevideo (1730-1808), Montevideo, Linardi y Risso, 2014.

Garavaglia, Juan Carlos, "El teatro del poder: Ceremonias, tensiones y conflictos en el Estado Colonial”, Boletín del instituto Dr. Emilio Ravignani n. ${ }^{\circ} 14$, Buenos Aires, 1996, pp. 7-30

Gómez González, Inés, La justicia en Almoneda. La venta de Oficios en la Chancillería de Granada (1505-1834), Granada, Comares, 2002.

Grenon, Pedro S. J., "Jesuitas santafesinos" en Revista de la Junta Provincial de Estudios Históricos de Santa Fe n. ${ }^{0}$, Santa Fe, 1936, pp.63-64.

Grenon, Pedro S. J., "Santafesinos universitarios", Revista de la Junta de Históricos de Santa Fe n. ${ }^{\circ}$, Santa Fe, 1940, pp.31-40.

Guerrero Elecalde, Rafael y Tarragó, Griselda, "La certera espacialidad de los vínculos: los Tagle Bracho entre la Montaña, Lima y el Río de la Plata (primera mitad del siglo XVIII)”, Prohistoria [online]. vol.18, Rosario, 2012, pp.1-24.

Hernández, Mauro, "Venalidad de oficios municipales en la Castilla del siglo XVIII: un ensayo de cuantificación", en Chronica Nova n. ${ }^{\circ} 33$, Granada, Universidad de Granada, 2007, pp.95-129. 
Jiménez Estrella, Antonio, "Poder, dinero y ventas de oficios y honores en la España del Antiguo Régimen: un estado de la cuestión", en Cuadernos de Historia Moderna n. ${ }^{0} 37$, Madrid, 2012, pp.259-272.

Mínguez, Víctor, Los reyes distantes. Imágenes del poder en el México virreinal, Castelló de la Plana, Universitat Jaume I, 1995.

Moriconi, Miriam, Política, piedad, jurisdicción. Cultura jurisdiccional en la Monarquía Hispánica. Siglos XVI-XVIII, Rosario, Prohistoria, 2011.

Moriconi, Miriam, "Usos de la justicia eclesiástica y de la justicia real (Santa Fe de la Vera Cruz, Río de la Plata, s. XVIII)”, Nuevo Mundo Mundos Nuevos [en línea], Debates, París, Puesto en línea el 27 octubre 2012, consultado el 11 junio 2013. http://nuevomundo.revues.org/64359.

Moriconi, Miriam, "Diversidad institucional y conflictos jurisdiccionales. El clero santafesino en el siglo XVIII", en Gabriela Alejandra Caretta y Isabel Zacca (comps.), Derroteros en la construcción de religiosidades sujetos, instituciones y poder en Sudamérica, siglos XVII al XXI, Salta, Centro Promocional de Investigaciones en Historia y Antropología -CEPIHA, 2012.

Moutoukias, Zacarías, "Gobierno y sociedad en el Tucumán y el Río de la Plata, 1550180o", en Enrique Tandeter (dir.), Nueva Historia Argentina. La Sociedad Colonial, Buenos Aires, Sudamericana, 2000, pp.355-411.

Ortemberg, Pablo (dir.), El origen de las fiestas patrias Hispanoamérica en la era de las independencias, Rosario, Prohistoria Ediciones, 2013.

Pastells, Pablo, Historia de la Compañía de Jesús en la provincia del Paraguay (Argentina, Paraguay, Uruguay, Perú, Bolivia y Brasil). Según los documentos originales del archivo general de indias extractados y anotados por el R.P. Pablo Pastells, S.J., Tomo III, Madrid, Librería General de Victoriano Suárez, 1918.

Quevedo, Roberto, Paraguay años 1671 a 1681, Asunción, El lector, 1983.

Rodríguez, Irene, Forconi, Celeste y Foglia, Daniela, "La venta de cargos y la administración de justicia en el siglo XvIII", en Darío Barriera (dir.), Economía y Sociedad (siglo XVI a XVIII), Nueva Historia de Santa Fe, Rosario, La Capital, 2006.

Saguier, Eduardo, Genealogía de la Tragedia Argentina. Auge y colapso de un fragmento de estado o la violeta transición de un orden imperial-absolutista a un orden nacional-republicano (1600-1900). www.er-saguier.org. 2007

Smietniansky, Silvina, Ritual, tiempo y poder. Una aproximación antropológica a las instituciones del gobierno colonial: Gobernación del Tucumán, siglos XVII y XVIII, Rosario, Prohistoria Ediciones, 2013. 
Socolow, Susan, Los mercaderes del Buenos Aires virreinal: familia y comercio, Buenos Aires, De la flor, 1991.

Spangerberg, Ernesto A., "Censo de encomenderos del Paraguay de 1674”, en Genealogía $\mathrm{n}^{\mathrm{o}}$ 32, Buenos Aires, 1992.

Stumpf, Roberta y Chaturvedula, Nandini (orgs.), Cargos e oficios nas Monarquías Ibéricas: provimento, controlo e venalidade (séculos XVII e XVIII), Lisboa, CHAM, 2012.

Tarragó, Griselda, "The long kiss of goodbye: Santa Fe and the conflict over the privilege of puerto preciso (1726-1743)", en Giuseppe de Luca y Gaetano Sabatini (eds.), Growing in the Shadow of an Empire. How Spanish Colonialism Affected Economic Development in Europe and in the World (XVIth-XVIIIth cc.), Milano, Franco Angeli Editore, 2012.

Tarragó, Griselda y Barriera, Darío, "Elogio de la incertidumbre. La construcción de la confianza, entre la previsión y el desamparo: Santa Fe y el Río de la Plata, siglo XVIII", en Revista de Historia n. ${ }^{\circ}$ 48, San José, Universidad Nacional de Costa Rica, 2003, pp.183-223.

Tau Anzoátegui, Víctor, El poder de la costumbre. Estudios sobre el derecho consuetudinario en América hispana hasta la Emancipación, Madrid, Ed. Fundación Histórica Tavera, 2000.

Tau Anzoátegui, Víctor y Martiré, Eduardo, Manual de historia de las instituciones argentinas, Séptima edición actualizada, Buenos Aires, Librería Histórica, 2005.

Tomás y Valiente, Francisco, La venta de oficios en Indias (1492-1606), Madrid, Instituto de Estudios Administrativos, 1972.

Tomás y Valiente, Francisco, Gobierno e Instituciones en la España del Antiguo Régimen, Madrid, Alianza, 1992. 